\title{
Cotinine Reduces Amyloid- $\beta$ Aggregation and Improves Memory in Alzheimer's Disease Mice
}

\author{
Valentina Echeverria ${ }^{\mathrm{a}, \mathrm{b}, \mathrm{c}, *}$, Ross Zeitlin ${ }^{\mathrm{a}, \mathrm{c}}$, Sarah Burgess $^{\mathrm{a}}$, Sagar Patel ${ }^{\mathrm{a}, \mathrm{c}}$, Arghya Barman $^{\mathrm{d}}$, \\ Garima Thakur ${ }^{\mathrm{d}}$, Magorzota Mamcarz ${ }^{\mathrm{c}, \mathrm{e}}, \mathrm{Li}^{\mathrm{W}} \mathrm{Wang}^{\mathrm{e}}$, David B. Sattelle ${ }^{\mathrm{f}}$, Daniel A. Kirschner ${ }^{\mathrm{g}}$, \\ Takashi Mori ${ }^{\mathrm{h}}$, Roger M. Leblanc ${ }^{\mathrm{d}}$, Rajeev Prabhakar ${ }^{\mathrm{d}}$ and Gary W. Arendash ${ }^{\mathrm{e}}$ \\ ${ }^{a}$ Bay Pines VA Healthcare System, Bay Pines, FL, USA \\ ${ }^{\mathrm{b}}$ Department of Molecular Medicine, University of South Florida, Tampa, FL, USA \\ ${ }^{\mathrm{c}}$ Research Service, Department of Veterans Affairs Medical Center, Tampa, FL, USA \\ ${ }^{\mathrm{d}}$ Department of Chemistry, University of Miami, FL, USA \\ ${ }^{\mathrm{e}}$ Department of Cell Biology, Microbiology \& Molecular Biology, University of South Florida, Tampa, FL, USA \\ ${ }^{\mathrm{f}}$ Faculty of Life Sciences, University of Manchester, Manchester, UK \\ ${ }^{\mathrm{g}}$ Department of Biology, Boston College, Massachusetts, USA \\ ${ }^{\mathrm{h}}$ Departments of Biomedical Sciences and Pathology, Saitama Medical Center and Saitama Medical \\ University, Kawagoe, Saitama, Japan
}

Accepted 23 January 2011

\begin{abstract}
Alzheimer's disease (AD) affects millions of people world-wide and new effective and safe therapies are needed. Cotinine, the main metabolite of nicotine, has a long half-life and does not have cardiovascular or addictive side effects in humans. We studied the effect of cotinine on amyloid- $\beta(\mathrm{A} \beta)$ aggregation as well as addressed its impact on working and reference memories. Cotinine reduced $A \beta$ deposition, improved working and reference memories, and inhibited $A \beta$ oligomerization in the brains of transgenic (Tg) $6799 \mathrm{AD}$ mice. In vitro studies confirmed the inhibitory effect of cotinine on $\mathrm{A} \beta_{1-42}$ aggregation. Cotinine stimulated Akt signaling, including the inhibition of glycogen synthase kinase $3 \beta$, which promotes neuronal survival and the synaptic plasticity processes underlying learning and memory in the hippocampus and cortex of wild type and $\operatorname{Tg} 6799$ $\mathrm{AD}$ mice. Simulation of the cotinine-A $\beta_{1-42}$ complex using molecular dynamics showed that cotinine may interact with key histidine residues of $A \beta_{1-42}$, altering its structure and inhibiting its aggregation. The good safety profile in humans and its beneficial effects suggest that cotinine may be an excellent therapeutic candidate for the treatment of AD.
\end{abstract}

Keywords: Alzheimer's disease, amyloid- $\beta$, cotinine, neurodegeneration, oligomerization

\section{INTRODUCTION}

Alzheimer's disease (AD) is the main cause of dementia in the elderly [1]. This devastating disease is

*Correspondence to: Valentina Echeverria, 10,000 Bay Pines Blvd. Bldg. 22 Rm. 123, Bay Pines, FL 33744, USA. Tel.: +1 727398 6661, ext. 4425; Fax: +1 727319 1161; E-mail: valentina.echeverria@va.gov. characterized by memory loss, synaptic dysfunction, and neuropathological changes, such as the presence of plaques of aggregated amyloid- $\beta$ (A $\beta$ ) peptide, amyloid angiopathy, and neurofibrillary tangles of phosphorylated tau protein in the brain $[2,3]$. At least some of the loss of cognitive abilities has been attributed to deterioration of the cholinergic system induced by the toxic forms of $\mathrm{A} \beta[1,4,5]$. The currently available treatments for $\mathrm{AD}$ include the use of 
acetylcholinesterase inhibitors (i.e., donepezil, galantamine, or tacrine) [6-9] and the N-methyl-D-aspartate (NMDA) antagonist, memantine. Unfortunately, these drugs only marginally ameliorate the cognitive deficits and have mostly short-term positive effects [6, 10-12].

Epidemiological studies have shown a negative correlation between tobacco consumption and the development of AD [13]. It has also been found postmortem that the levels of soluble and insoluble $A \beta$ peptides were significantly decreased in the brains of smoking $\mathrm{AD}$ patients compared to non-smokers with the disease [14]. The putative beneficial effect of tobacco has been mainly attributed to nicotine, which has been reported to improve cognitive abilities and reduce plaques in a mouse model of AD [15]. Since nicotinic receptors play an important role in attention, learning, and memory, the positive effects of nicotine on memory were mostly credited to the activation of these receptors. Unfortunately, due to its toxicity, addictive properties, and side effects, nicotine has not been considered an attractive therapeutic agent against AD [16-18].

In mammals, more than $80 \%$ of nicotine is metabolized into cotinine, a metabolite with a longer half-life (nicotine, 2-3 h; cotinine, 19-24h) and much lower toxicity [19]. For these reasons, we speculate that the effects attributed to nicotine in vivo may be at least in part due to cotinine, which persists for longer in the brain. However, cotinine is a very weak agonist of nicotinic acetylcholine receptors (nAChRs) [20-22], and thus the mechanism of its possible beneficial effects on memory has been elusive and controversial $[23,24]$.

Here, we examined the actions of cotinine on plaque deposition and cognitive impairment using the amyloid- $\beta$ protein precursor (A $\beta P P) /$ presenilin 1 (PS1) transgenic (Tg) 6799 mice, which express 5 familial AD (FAD) mutations [25]. We use the Tg6799 model because these mice show measurable whole brain levels of $A \beta$ and brain $A \beta$ deposition by 2-4 months, and fast cognitive impairment by 4-8 months of age [26, 27]. We have also explored Akt activation by phosphorylation in the hippocampus and cortex of mice treated with cotinine. We investigated Akt because it is critically involved in neuronal survival and mediates synaptic plasticity changes during learning and memory processes [28]. For example, Akt targets pro-apoptotic proteins, such as Bcl-2 and caspase-9, protecting neurons from apoptosis [29] and inhibits the pro-apoptotic tau kinase, glycogen synthase kinase $3 \beta$ (GSK $3 \beta$ ) by phosphorylation $[30,31]$. Finally, to understand the effect of cotinine on $A \beta$ plaque depo- sition, we also investigated the effects of cotinine on $\mathrm{A} \beta$ aggregation in vitro and model the interaction of cotinine with $A \beta_{1-42}$.

We found that cotinine reduced cerebral $A \beta$ deposition and ameliorated cognitive impairment in $\mathrm{Tg}$ mice. These beneficial actions may result from its capacity to reduce $A \beta$ aggregation. Computational modeling of the cotinine-A $\beta_{1-42}$ complex suggests that cotinine's inhibition of $A \beta$ aggregation may be related to its ability to bind to amino acid residues that participate in the aggregation of the peptide. The implications of these findings for developing a new therapy for $\mathrm{AD}$ are discussed.

\section{MATERIALS AND METHODS}

\section{Drugs}

Cotinine was purchased from Sigma-Aldrich Corporation (St. Louis, MO).

Mice

We used the Tg6799 mice, which express the human A $\beta P P$ and PS1 genes containing five FAD mutations [25], including three FAD mutations in A $\beta P P$ (Swedish mutation: K670N, M671L; Florida mutation: I716 V; London mutation: V717I) and two in PS1 (M146L, L286 V) (The Jackson Laboratories, Bar Harbor, ME) [26]. The Tg6799 lines were maintained as hemizygotes on a B6/SJL hybrid background. Male mice were used as heterozygotes with respect to the transgene and non-Tg (NT) wild type littermate mice served as controls. All behavioral analyses were performed between 5.5 and 6.5 months of age by investigators blind to the genotype and treatment of mice. Mice were maintained on a 12-h dark and 12-h light cycle with ad libitum access to food and water. All protocols were previously approved by the Institutional Animal Care and Use Committees of the University of South Florida and Bay Pines Veterans Affairs Healthcare System.

\section{Cotinine treatment}

At 2 months of age, Tg mice were started on daily treatment with cotinine $(2.5 \mathrm{mg} / \mathrm{kg})$ dissolved in PBS or vehicle alone orally via gavage. Treatment was administered for 3.5 months, as well as for the ensuing one-month period of behavioral testing and subsequently for two weeks until euthanasia (total of 5 months of treatment). 


\section{Behavioral testing}

A one-month battery of sensorimotor, anxiety, and cognitive-based tasks was performed beginning at 3.5 months into treatment (5.5 months of age) [32, 33]. In the order of their performance, the tasks administered were: sensorimotor (open field, balance beam, string agility, and Y-maze), anxiety (elevated plus maze), and cognition-based [Morris water maze (MWM), circular platform, platform recognition, radial arm water maze (RAWM)] [32], and cognitive interference [33]. Since there were no transgene or treatment effects on any of the sensorimotor or anxiety tasks, and there were no cognitive effects of treatment observed in NT or Tg mice in MWM or platform recognition, we only describe the three cognitive tasks that did exhibit significant effects of treatment (circular platform, RAWM, and cognitive interference) as detailed below.

\section{Circular platform (spatial reference \\ learning/memory)}

A walled $69 \mathrm{~cm}$ circular platform, with 16 equidistantly spaced holes along its periphery, was encircled by a black curtain [34]. Visual cues, located on the black curtain and platform walls can be used by the animal to find the one hole through which it can escape the platform surface to avoid the aversive stimuli of bright lights and fan wind. During a single 5-min maximum daily trial, the total number of errors (head pokes into non-escape holes) and latency to find the escape hole were recorded. Although the escape hole remained constant for any given animal over the 8 days of testing, it was relocated after each animal's trial to control for olfactory cues. To minimize interference from olfactory cues, the maze was cleaned with a dilute vinegar solution following each animal's trial. Performance for four 2-day blocks of testing was analyzed statistically with Analysis of Variance (ANOVA), followed by post hoc comparisons done with the Fisher's least significant difference test.

\section{Radial arm water maze (working memory)}

For the RAWM task of spatial working memory, an aluminum insert was placed into a $100 \mathrm{~cm}$ circular pool to create 6 radially distributed swim arms emanating from a central circular swim area [32]. An assortment of 2-D and 3-D visual cues surrounded the pool. The latency and number of errors prior to locating which one of the 6 swim arms contained a submerged escape platform $(9 \mathrm{~cm}$ diameter) was determined for 5 tri- als/day over 8 days of testing, with statistical analysis involving performance over all 8 days of RAWM performance. There was a 30-min time delay between the 4th trial (T4; final acquisition trial) and 5th trial (T5; memory retention trial). The platform location was changed daily to a different arm, with different start arms for each of the 5 trials semi-randomly selected from the remaining 5 swim arms. During each trial (60-s maximum), the mouse was returned to that trial's start arm upon swimming into an incorrect arm and the number of seconds required to locate the submerged platform was recorded. If the mouse did not find the platform within a 60-s trial, it was guided to the platform for the 30-s stay. The latency and number of errors during T4 and T5 are both considered indices of working memory and are temporally similar to the standard registration/recall testing of specific items used clinically in evaluating AD patients.

\section{Cognitive interference task (proactive/retroactive interference)}

We designed this task based on a cognitive task used to discriminate normal aged, mild cognitive impairment, and $\mathrm{AD}$ patients from one another [35]. Our interference task for mice involves two RAWM setups in two different rooms, each with different sets of visual cues [33]. The task requires animals to remember a set of visual cues, so that following interference with a different set of cues, the initial set of cues can be recalled to successfully solve the RAWM task. A set of four behavioral measures was examined. Behavioral measures were: A3 (the last of three recall trials performed in RAWM "A"), "B" (proactive interference measure attained from a single trial in RAWM "B"), A4 (retroactive interference measure attained during a single trial in RAWM “A"), and "A5" (delayedrecall measure attained from a single trial in RAWM "A" following a 20-min delay between A4 and A5). As a distraction between trials, animals are placed in a Y-maze and allowed to explore for $60 \mathrm{~s}$ between successive trials of the three-trial recall task, as well as during the proactive interference task. As with the standard RAWM task, this interference task involves the platform location being changed daily to a different arm for both of the RAWM set-ups utilized, and different start arms for each day of testing for both RAWM set-ups. For A1 and B trials, the animal was initially allowed one min to find the platform on their own before they were guided to the platform. The actual trial was then performed in each case. As with the standard RAWM task, animals were given $60 \mathrm{~s}$ to find the escape platform for each trial, with the number 
of errors and escape latency recorded for each trial. Given the very close correspondence between error and latency scores in individual animals for both the RAWM and cognitive interference tasks, only latency scores are presented in this report. Animals were tested for cognitive interference performance on two successive days, with statistical analysis performed on the resultant 2-day block.

\section{Brain tissue preparation}

Following behavioral testing of seven-month-old mice, animals were euthanized and perfused with a cold physiological saline. The left frontal half of each brain was placed in $4 \%$ paraformaldehyde in $0.1 \mathrm{M}$ phosphate buffer ( $\mathrm{pH}$ 7.4) overnight, wherein tissues remained until the paraffin embedding process for $A \beta$ immunohistochemical analyses. The remaining left portion of the brain, as well as the entire right side of the brain, was dissected out into regions (e.g., hippocampus and cortex), quickly frozen, and stored at $-80^{\circ} \mathrm{C}$ for later neurochemical analyses.

\section{Western blot analysis of tissue extracts}

Tissues were analyzed by Western blot as previously described [33]. Briefly, brains were rapidly removed, and tissues dissected and disrupted by sonication in radioimmunoprecipitation assay (RIPA) buffer (Tris $50 \mathrm{mM}$ pH 7.4; $\mathrm{NaCl} 150 \mathrm{mM}$; SDS 0.1\%; NaDeoxycholate 0.5\%; Triton X-100 1\%; Cell Signaling Technology, Danvers, MA) with a complete protease inhibitor cocktail (Roche Molecular Biochemicals, Indianapolis, IN). Brain extracts were incubated on ice for $30 \mathrm{~min}$ and centrifuged at $20,000 \times g$ for $30 \mathrm{~min}$ at $4{ }^{\circ} \mathrm{C}$. Equal amounts of protein from the supernatant were separated by sodium dodecyl sulfate-polyacrylamide gel electrophoresis (SDSPAGE) using either 10-20\% Tris-Tricine gel (Bio-Rad Laboratories, Inc., Hercules, CA) for A $\beta P P / A \beta$ analyses or $4-20 \%$ Tris-Glycine gel (Thermo Fisher Scientific Inc., Rockford, IL) for Akt and $\beta$-tubulin analyses and transferred to nitrocellulose membranes. The membranes were blocked in TBS with $0.05 \%$ Tween 20 (TBST; Bio-Rad Laboratories, Inc.) containing $10 \%$ dry skim milk and incubated in TBST with primary antibodies overnight at $4{ }^{\circ} \mathrm{C}$ and secondary antibodies for $1 \mathrm{~h}$ at RT. Rabbit monoclonal antibodies directed against Akt phosphorylated at serine 473 (pAkt [Ser473]) $(1: 500)$ and total Akt $(1: 1,000)$ were obtained from Cell Signaling Technology. A rabbit polyclonal antibody directed against phospho-
GSK3 $\beta$ (Serine 9) and total GSK3 $\beta$ were obtained from Cell Signaling Technology. A mouse monoclonal antibody directed against $\mathrm{A} \beta$ (6E10) $(1: 5,000$; Covance, Emeriville, $\mathrm{CA}$ ) that also recognizes A $\beta P P$ and several forms of the peptide was used to detect $\mathrm{A} \beta$ oligomers. A monoclonal mouse antibody against $\beta$-tubulin (1 : 10,000; Promega, Madison, WI) was used to control protein sample loading and transfer efficiency. The monoclonal antibody against total AßPP (clone 22C11) (1:2,000; Millipore, Temecula, CA) was used to confirm the immunoreactivity of total A $\beta P P$. Membranes were washed with TBST and incubated with LI-COR's goat anti-mouse IRDye secondary antibodies (LI-COR Biosciences, Lincoln, NE) for $1 \mathrm{~h}$, washed with TBST and TBS, and images were acquired using an Odyssey Infrared Imaging System (LI-COR Biosciences) or the Kodak Image Station 440CF (Eastman Kodak Company, Rochester, NY) using a Molecular Imaging Software version 4.0 (Eastman Kodak Company), and analyzed using an NIH Image $\mathbf{J}$ software.

\section{Analysis of cotinine levels in the brain}

The levels of cotinine in brain tissues of mice were estimated using ELISA. Briefly, after treatments and behavioral testing, mice were euthanized, and brains were removed, dissected, and disrupted by sonication in RIPA buffer (Cell Signaling Technology) containing a complete protease inhibitor cocktail (Roche Molecular Biochemicals). Cortical extracts were incubated on ice for $30 \mathrm{~min}$ and centrifuged at $20,000 \times \mathrm{g}$ for $30 \mathrm{~min}$ at $4^{\circ} \mathrm{C}$. The resultant supernatants were used to determine cotinine levels according to the manufacturer's instructions using a commercial ELISA kit (Calbiochem, San Diego, CA). In this solid phase competitive ELISA, the cotinine present in the samples competes with a cotinine-enzyme conjugate for the binding to a plate coated with anti-cotinine antibody. Upon the addition of the substrate for the conjugated enzyme (horseradish peroxidase), the concentration of the cotinine in the samples is inversely proportional to the intensity of the color developed in the wells.

\section{Analysis of $A \beta$ levels}

The levels of $A \beta_{40}$ and $A \beta_{42}$ were quantified in brain tissues by ELISA. To determine soluble A $\beta$ levels, brain tissues were homogenized in RIPA buffer, centrifuged at $20,000 \times g$ for $20 \mathrm{~min}$ at $4^{\circ} \mathrm{C}$ and the supernatants were stored at $-80^{\circ} \mathrm{C}$ until use. To mea- 
sure insoluble $A \beta$ levels, brain tissues were prepared by sonication of the samples in a solution of $5 \mathrm{M}$ guanidine $\mathrm{HCl}$ (Sigma-Aldrich Corporation) ( $\mathrm{pH}$ 8.0). After sonication, samples were incubated for $3 \mathrm{~h}$ at RT and centrifuged at $20,000 \times \mathrm{g}$ for $20 \mathrm{~min}$ at $4^{\circ} \mathrm{C}$. The supernatants were stored at $-80^{\circ} \mathrm{C}$ until use or immediately diluted using PBS with $5 \%$ bovine serum albumin (Sigma-Aldrich Corporation) and $0.03 \%$ Tween 20 supplemented with $1 \times$ protease inhibitor cocktail (Roche). Then samples were analyzed for $A \beta$ levels using an ELISA kit (Invitrogen Corporation, Carlsbad, $\mathrm{CA}$ ), according to the manufacturer's recommendations.

\section{A $\beta$ plaque analysis}

For brain $A \beta$ immunohistochemical staining and analysis, we used our well-established protocol as previously described [32]. Briefly, the frontal cortex from the left side of the brain was dissected. At the level of cingulate and motor cortex, three 5- $\mu \mathrm{m}$ sections $(150 \mu \mathrm{m}$ apart) were made from each mouse brain using a sliding microtome. Immunohistochemical staining was performed using a Vectastain $\mathrm{ABC}$ Elite kit (Vector Laboratories, Burlingame, CA) coupled with the diaminobenzidine reaction, except that the biotinylated secondary antibody step was omitted for $A \beta$ immunohistochemical staining. A biotinylated human A $\beta$ monoclonal antibody (clone 4G8; $1: 200$, Covance Research Products, Emeryville, CA) was incubated for $1 \mathrm{~h}$ at RT. PBS ( $\mathrm{pH}$ 7.4) or normal rabbit serum was used instead of primary antibody or $\mathrm{ABC}$ reagent as a negative control. Brain sections were treated with $70 \%$ formic acid prior to the preblocking step. Quantitative image analysis utilized previous methods with modifications [36, 37]. Images were acquired using an Olympus BX60 microscope with an attached digital camera system (DP-70, Olympus, Tokyo, Japan), and the digital image was routed into a Windows PC for quantitative analysis using a SimplePCI software (Hamamatsu Photonics, Hamamatsu, Shizuoka, Japan). Images of three sections through both anatomic regions of interest (cingulate and motor cortices) were captured from each animal, and a threshold optical density was obtained that discriminated staining from background. Each region of interest was manually edited to eliminate artifacts. For $\mathrm{A} \beta$ burden analysis, data are reported as percentage of immunolabeled area captured (positive pixels) relative to the full area captured (total pixels). Each analysis was done by a single investigator blinded to sample identities.
Dot blot analysis of A $\beta$ oligomers in brain tissues of Tg6799 mice

To investigate the effect of cotinine on the formation of soluble $A \beta$ oligomers, we performed dot blot analysis using the A11 antibody (1:1,000; Invitrogen Corporation), which is highly specific for the oligomeric forms of $A \beta$ and does not recognize the monomeric or fibrillar forms of the peptide. Briefly, hippocampal tissues were disaggregated using a pellet pestle in RIPA buffer and centrifuged at $20,000 \times g$ for $30 \mathrm{~min}$. Aliquots of hippocampal extract supernatants ( $2 \mu \mathrm{g}$ protein) were applied onto nitrocellulose membranes and allowed to dry, after which the membranes were blocked for $1 \mathrm{~h}$ at RT with LI-COR blocking buffer, washed, and incubated with A11 antibody overnight at $4^{\circ} \mathrm{C}$. After washing, membranes were incubated with LI-COR's IRDye secondary antibodies for $1 \mathrm{~h}$ and then washed. The immunoreactive dots were then visualized using an Odyssey Infrared Imaging System (LI-COR Biosciences) and analyzed with an NIH Image $\mathbf{J}$ software.

\section{Western blot analysis of $A \beta$ oligomers}

The Western blot analysis was performed as described previously [38]. Briefly, hippocampal tissues were disaggregated with a pellet pestle in RIPA buffer and centrifuged at $20,000 \times g$ for $30 \mathrm{~min}$. Aliquots of hippocampal extract supernatants $(80 \mu \mathrm{g}$ protein) were mixed with Tris-Tricine $3 \times$ sample buffer (Bio-Rad Laboratories, Inc.), separated in a 10-20\% Tris-Tricine gel by electrophoresis, and blotted using the $6 \mathrm{E} 10$ antibody $(1: 5,000)$. The membranes were incubated with horseradish peroxidase-conjugated secondary antibody for $1 \mathrm{~h}$, visualized using Enhanced Chemiluminiscence (SuperSignal Femto Maximum Sensitivity Substrate, Pharmacia Biotech, Piscataway, NJ), scanned on the Kodak Image Station 440CF (Eastman Kodak Company) using a Molecular Imaging Software version 4.0 (Eastman Kodak Company), and analyzed with an NIH Image J software.

\section{AFM analysis of the effect of cotinine on $A \beta$ aggregation}

\section{Preparation of $A \beta$ solutions for atomic force microscopy (AFM)}

To investigate the effect of cotinine on $A \beta$ fibrillation, we prepared the $A \beta_{1-42}$ solutions using a method that permits a fast development of fibrils. 
The first step of this protocol consists in dissolving $\mathrm{A} \beta_{1-42}$ in 1,1,1,3,3,3-hexafluoroisopropanol (HFIP; Sigma-Aldrich Corporation) to obtain a starting solution containing only $A \beta_{1-42}$ monomers [39]. Briefly, lyophilized $A \beta_{1-42}$ (American Peptide) was dissolved in HFIP, evaporated, re-dissolved in dimethyl sulfoxide (DMSO) (Sigma-Aldrich Corporation), and then diluted in PBS (pH 7.4) alone or plus cotinine. Peptide solutions containing $A \beta_{1-42}(1 \mathrm{mM})$ with and without cotinine $(2 \mathrm{mM})$ were incubated for 10 days at RT and the formation of oligomers and fibers was examined by AFM.

\section{AFM analysis}

20- $\mu$ l aliquots of $A \beta$ solutions were deposited on freshly cleaned and dried silicon wafers (approximately $1-\mathrm{mm}$ thick). After waiting for $10 \mathrm{~min}$, nonadsorbed portions of the samples were washed with de-ionized water $(2 \mathrm{ml})$. The wet surface of the silicon wafer was then dried using a gentle flow of air. The AFM analysis was performed using an AFM apparatus (AFM, BA multimode SPM, Model no. 920-006-101, Veeco, Plainview, NY) that permits the acquisition of images using a tapping mode approach. This approach allows intermittent contact of the tip with the sample and minimizes the chances of deformation of the peptide samples. The cantilever and the tip were made of silicon and the cantilever force constant was approximately $20-100 \mathrm{~N} / \mathrm{m}$ with the resonance frequency between 200 and $400 \mathrm{kHz}$. The scan rate was $1.0 \mathrm{~Hz}$. The analysis of fibrils and oligomers was performed using the Nanoscope Control software (version 5.30) (Veeco). The analysis of the height of the aggregates was performed using Pico Image software (Pico View version 1.6.4) from Agilent Technologies (Mississauga, ON, Canada).

\section{Molecular modeling}

The chemical structure of cotinine is similar to that of nicotine, and also possesses two different enantiomers (i.e., $\mathrm{S}$ and $\mathrm{R}$ forms). As the exact binding site of cotinine on $A \beta_{1-42}$ is not known, the binding site of nicotine on $A \beta_{1-42}$ was used to develop starting models for the molecular dynamics (MD) simulations. Because S-cotinine was used in the experiments reported in this study, we utilized this form of cotinine in the simulations on the cotinine- $\mathrm{A} \beta_{1-42}$ complex. The molecular modeling of the interaction between cotinine and the $A \beta_{1-42}$ monomer was performed in the following two steps.

\section{Molecular docking}

Cotinine was docked near the His13 and His14 residues of the full-length $A \beta_{1-42}$ peptide using the AutoDock program (version 4.0. The Scripps Research Institute, La Jolla) [40]. The most representative structure obtained from the previous 50-ns MD simulations on full-length $A \beta_{1-42}$ in aqueous solution was used in the docking procedure [41]. The reported binding sites of nicotine on $A \beta_{1-42}$ were utilized in this process [42-44]. The AutoDock program performed the rapid energy evaluation through a pre-calculated grid and found the suitable binding position of cotinine on $A \beta_{1-42}$. Polar hydrogens were added using the hydrogen module in the AutoDock tools for the peptide and the Kollman united atom partial charges were assigned. The grid was calculated using the Auto Grid protocol. It was chosen to include all the His residues (His6, His13, and His14) of $A \beta_{1-42}$. The dimension of the grid was set to $50 \times 50 \times 50 \AA$ with a spacing of $0.375 \AA$ between the two consecutive grids. In the docking process, $A \beta_{1-42}$ was kept rigid and cotinine was allowed to form all the possible torsional bonds. The AutoDock Lamarckian genetic algorithm using the standard protocol with 150 randomly placed individual initial populations was applied. In total, 50 independent docking runs were performed. The lowest energy conformer taken from the docked complex was utilized to perform 50-ns MD simulations on the cotinine- $A \beta_{1-42}$ complex in aqueous solution.

\section{Molecular dynamics simulations}

All MD simulations were performed using a GROMACS software package (General Public License), utilizing the GROMACS force field [45]. Dundee Pro Drug Server was used for generating the topology of the cotinine molecule for the MD simulation and the partial charges were also calculated using this server [46]. The cotinine-A $\beta_{1-42}$ complex was placed in the center of a box with dimensions $4.9 \times 4.2 \times 4.6 \mathrm{~nm}$. The box contained over 2,852 single point charge water molecules. Some water molecules were replaced by sodium and chloride ions to neutralize the system and to simulate an experimentally used ion concentration of $150 \mathrm{mM}$. The starting structure was subsequently energy minimized with a steepest descent method for 2,000 steps. The results of these minimizations produced the initial structure for the MD simulations. The MD simulations were then carried out with a constant number of particles, pressure, and temperature. The SETTLE algorithm was used to constrain the bond length and angle of the water molecules [47], while the LINCS algorithm was used to constrain the bond 
length of the peptide [48]. The long range electrostatic interactions were calculated by the particle-mesh Ewald method [49, 50]. A constant pressure of 1 bar was applied with a coupling constant of $1.0 \mathrm{ps}$; peptide, water molecules, and ions were coupled separately to a bath at $300 \mathrm{~K}$ with a coupling constant of $0.1 \mathrm{ps}$. The periodic boundary conditions were applied and the equation of motion was integrated at time-steps of $2 \mathrm{fs}$. The secondary structure analyses were performed by employing the defined secondary structures of proteins protocol [51]. The contact maps and similarity factor of the most representative structures obtained from a cluster analysis have also been employed as structural descriptors. A contact for a pair of amino acid side chains is considered to form when a minimal distance between any pair of their atoms is less than $0.5 \mathrm{~nm}$. In the cluster analysis, the trajectories were analyzed by grouping structurally similar frames [root-meansquare-deviation $(\mathrm{RMSD})$ cutoff $=0.30 \mathrm{~nm}$ [52]], and the frame with the largest number of neighbors is denoted as a "middle" structure, which represents that particular cluster.

\section{RESULTS}

\section{Cotinine improves cognitive performance in Tg6799 mice}

In a one-month battery of cognitive tasks administered between 5.5 and 6.5 months of age, there were no transgene or cotinine treatment effects on sensorimotor or anxiety function. There were also no effects of cotinine on several basic cognitive tasks (MWM and Platform recognition). However, significant effects of cotinine were detected in three other tasks (Fig. 1A-C). In the circular platform task of spatial reference memory, $\mathrm{Tg}$ controls were severely

\section{Circular Platform Final Block}

A

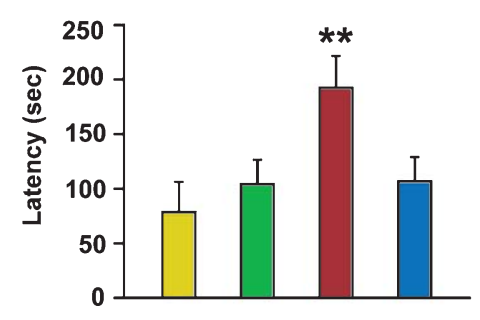

B

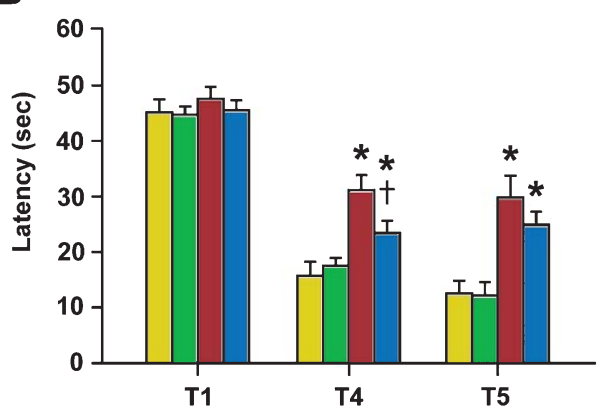

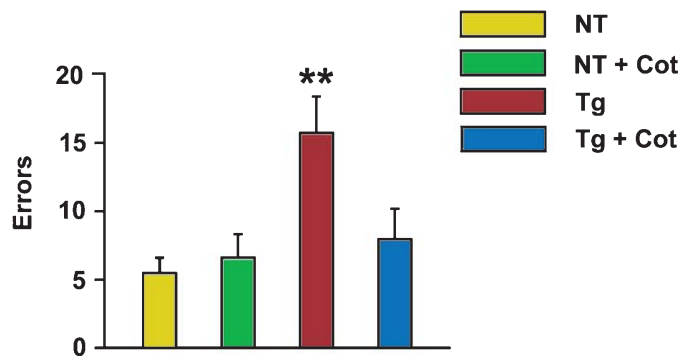

C

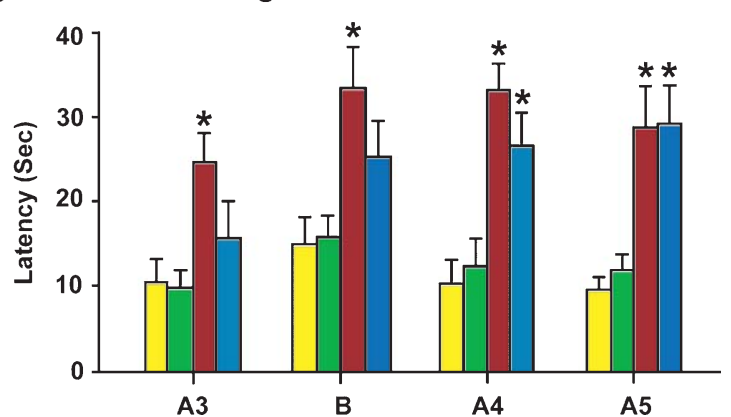

Fig. 1. Cotinine prevented cognitive impairment in Tg6799 mice. Long-term cotinine treatment $(2.5 \mathrm{mg} / \mathrm{kg}) \mathrm{protected}$ transgenic (Tg) mice ( $n=9-11)$ against cognitive impairment in multiple tasks of cognitive function. A) In the circular platform test of reference learning/memory, cotinine-treated $\mathrm{Tg}$ mice performed significantly better than $\mathrm{Tg}$ controls and no different from non-transgenic $(\mathrm{NT})$ controls $(n=9-11)$. ** $p<0.025$ or higher level of significance $v s$. cotinine-treated Tg mice and NT controls. B) Radial arm water maze testing for working memory revealed that cotinine-treated Tg mice again were superior to Tg controls, although they did not perform to the level of NT controls $\left({ }^{\dagger} p<0.02 v s\right.$. $\left.\mathrm{Tg} ;{ }^{*} p<0.025 v s . \mathrm{NT}\right)$. C) In the cognitive interference task, Tg controls were impaired on all four measures, whereas cotinine-treated Tg mice were no different from NT controls on A3 (Recall) and B (proactive interference) and nearly better than Tg controls in these two measures. For A4 (retroactive interference) and A5 (delayed recall), both groups of Tg mice were equally impaired ( $* p<0.05$ or higher level of significance vs. NT). ANOVA was used for statistical analysis of performance of four 2-day testing blocks, followed by post hoc comparisons done with the Fisher's least significant difference test. 
impaired in performance, as indicated by their much higher number of errors and latencies during the final block of testing (Fig. 1A). In sharp contrast, Tg mice that had been chronically treated with cotinine exhibited error and latency scores that were significantly lower and no different from NT controls. Cotinine treatment did not affect performance of NT mice in this any task of the entire test battery.

In the RAWM task of working memory, a modest beneficial effect of cotinine treatment was present in Tg mice for working memory trial T4 (Fig. 1B). Across all 8 days of testing, Tg6799 controls were significantly impaired (versus NT groups) during trial T4, while cotinine-treated $\mathrm{Tg}$ mice were significantly better than Tg6799 controls. Nonetheless, cotinine-treated $\mathrm{Tg}$ mice were not at the performance level of NT controls on T4. For delayed working memory trial T5, both $\mathrm{Tg}$ groups were impaired in performance.

As a more challenging variant of the RAWM task, the cognitive interference task evaluates not only working memory, but proactive and retroactive interference as well. Over both days of cognitive interference testing, $\mathrm{Tg}$ mice were impaired in all four measures evaluated in comparison to the excellent performance of NT controls. By contrast, Tg mice chronicallytreated with cotinine were no different from NT controls for both the final recall trial (A3) and the proactive interference trial (B) (Fig. 1C). As well, the performance of cotinine-treated $\mathrm{Tg}$ mice on these trials trended to be significantly different from Tg controls at $p=0.08$ and 0.13 , respectively. For the remaining two measures of cognitive interference (i.e., retroactive interference and delayed recall), cotinine treatment did not provide any cognitive benefit, with performance of treated Tg6799 mice being impaired and no different from control $\mathrm{Tg}$ mice.

Thus, long-term cotinine treatment to $\mathrm{Tg}$ mice provided complete protection from spatial reference memory impairment in the circular platform task, while also improving the performance of $\mathrm{Tg}$ mice to the level of NT controls in two working memory and cognitive interference tasks.

\section{Effect of cotinine on Akt phosphorylation}

We investigated the effect of cotinine on the activation of Akt by phosphorylation in the hippocampus and cortex of Tg and NT mice. The results show that cotinine stimulates Akt in both tissues. For vehicletreated Tg mice, the levels of the active form of Akt (pAkt [Ser473]) in the hippocampus and cortex were similar to the values found in the vehicle-treated NT mice, considered as 100\% immunoreactivity (Fig. 2A and B). By contrast, the treatment of $\mathrm{Tg}$ mice with cotinine $(2.5 \mathrm{mg} / \mathrm{kg})$ significantly increased the levels of pAkt [Ser473] in the hippocampus and cortex by $+51 \%(p=0.023)$ and $+189 \%(p=0.019)$, respectively, as normalized to total Akt levels (Fig. 2A and B). For NT mice, cotinine also induced a significant increase in the levels of pAkt [Ser473] in the hippocampus $(+74 \%$, $p=0.023)$ and cortex $(+205 \%, p=0.033)$ (Fig. $2 \mathrm{C}$ and D). When normalized against tubulin, no significant changes in the levels of total Akt were observed in the cotinine-treated $\mathrm{Tg}$ mice when compared to untreated Tg mice (Fig. 2A and B). However, we observed a highly significant increase in total levels of Akt as normalized against tubulin in the Tg mice when compared to NT mice in the hippocampus $(+49 \%, p=0.0043)$ (Fig. 2A). This increase was not observed in the frontal cortex of the same mice (Fig. 2B). We did not find changes in total Akt in cotinine-treated NT mice when compared to untreated NT mice in hippocampus and cortex (Fig. 2C and D).

\section{Effect of cotinine on the inhibition of GSK3 $\beta$ by phosphorylation}

Over-activation of GSK $3 \beta$ has been associated with tau hyperphosphorylation and neuronal cell death in AD brains [53]. It is well-known that Akt inactivates GSK3 $\beta$ by phosphorylation at Ser 9. Thus, based on our previous finding that cotinine activated Akt, we investigated the effect of cotinine on GSK3 $\beta$ phosphorylation in the brains of Tg6799 mice. First, we found no significant changes in the levels of pGSK3 $\beta$ [Ser9] normalized to total GSK3 $\beta$ in both the hippocampus and cortex of control $\mathrm{Tg}$ mice compared to control NT mice (Fig. 3A and B). However, cotinine treatment resulted in a significant increase in the levels of pGSK3 $\beta$ [Ser9] in the hippocampus of Tg mice $(+42 \%, p=0.035)$ with respect to vehicle-treated $\mathrm{Tg}$ mice (Fig. 3A). Also, a significant increase in the levels of pGSK3 $\beta$ [Ser9] was observed in the hippocampus of cotinine-treated NT mice compared to NT controls $(+56 \%, p=0.048)$ (Fig. 3C). Similarly, in the cotininetreated Tg mice we observed a trend of increase in the levels of pGSK3 $\beta$ [Ser9] in the frontal cortex when compared to vehicle-treated Tg mice, but the differences did not reach significance $(+54 \%, p=0.059)$ (Fig. 3B). However, cotinine treatment significantly increased the levels of pGSK3 $\beta$ [Ser9] in the cortex of NT mice compared to untreated otherwise identical mice $(+295 \%, p=0.0056)$ (Fig. 3D). No significant differences in the levels of total GSK3 $\beta$ were found in 

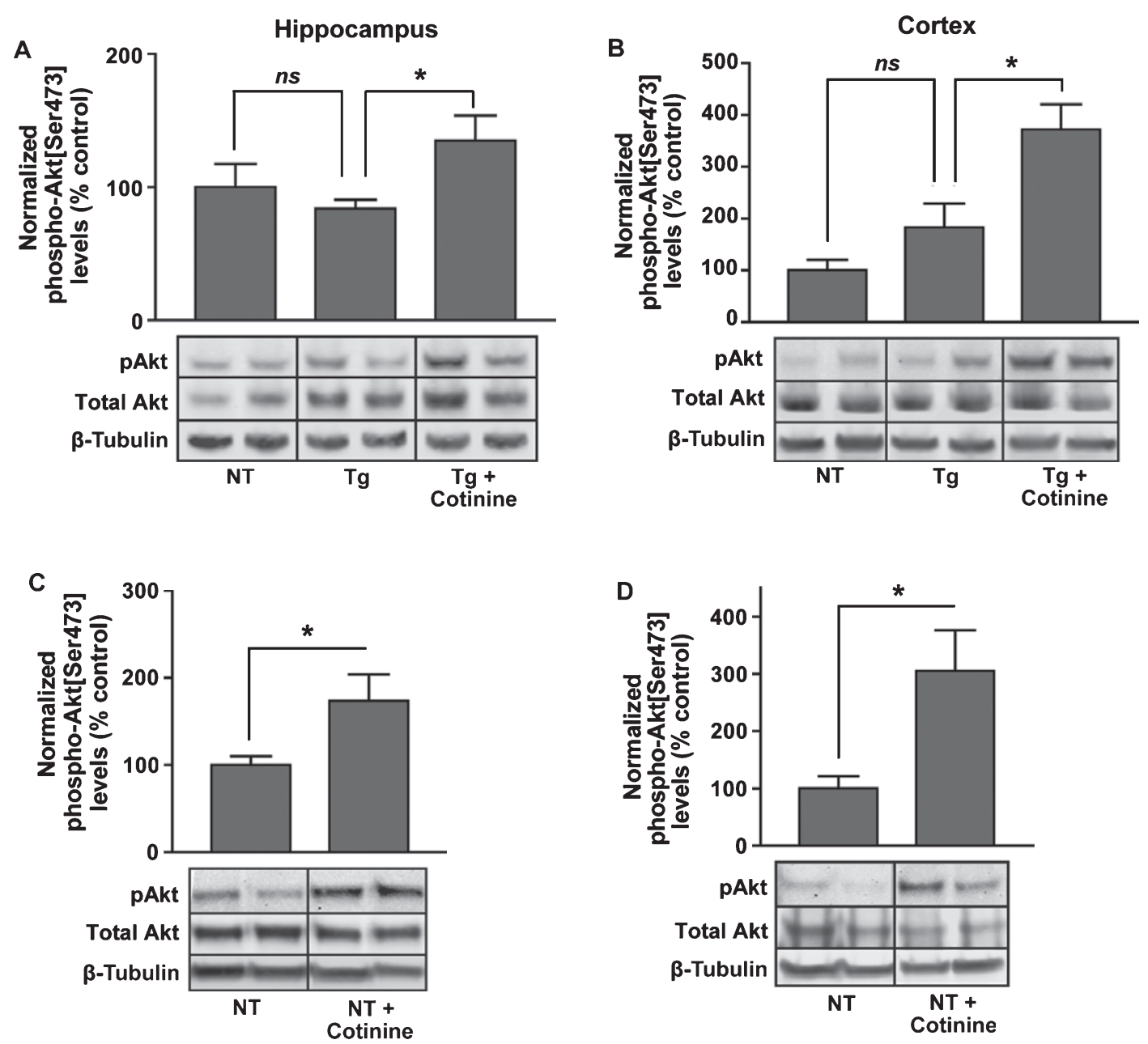

Fig. 2. Cotinine increased the active form of Akt in the brains of Tg6799 and non-transgenic (NT) control littermate mice. Tg and NT control littermate mice were treated with saline or cotinine $(2.5 \mathrm{mg} / \mathrm{kg}$ ) for 5 months and RIPA-soluble hippocampal and cortical protein extracts were analyzed by Western blot using antibodies against $\beta$-tubulin as well as total and phosphorylated Akt. The plots represent the immunoreactivity values expressed as percentage of control of saline-treated NT mice. Levels of normalized phospho-Akt [Ser473] immunoreactivity against total Akt levels in hippocampal (A, C) and cortical extracts (B, D) are shown. There was a clear activation of the Akt in the hippocampus and cortex of both Tg (hippocampus, $n=7-8$; cortex, $n=7-9$ ) and NT (hippocampus, $n=8-9$; cortex, $n=4-6$ ) mice. Dividing lines separate immunoreactive bands from different parts of the same membrane. The data are expressed as the mean \pm SEM. Student's $t$-test was used to compare the mean of the values between groups. $n s$, non-significant change; $* p<0.05$. pAkt, phospho-Akt [Ser473].

the hippocampus or cortex among groups of NT mice (data not shown).

\section{Effect of cotinine on A $\beta$ levels in the brains of Tg6799 mice}

To investigate the effect of cotinine on $A \beta$ levels, we analyzed the levels of $A \beta$ in the RIPA-soluble and insoluble fractions of cortex and hippocampus tissues of $\mathrm{Tg}$ mice treated with cotinine or vehicle for 5 months. It has been shown that in $\mathrm{AD} \mathrm{Tg}$ mice, the Swedish mutation increases the synthesis of total A $\beta$, whereas A $\beta P P$ London, Florida, and PS1 mutations promote the synthesis of $A \beta_{42}$ [25]. In coherence with this previous evidence, we found that the levels of $A \beta_{42}$ were substantially higher than the levels of $A \beta_{40}$ in both the hippocampus and cortex of 7-month-old Tg6799 mice (Table 1). The insoluble $A \beta_{42}$ levels were significantly decreased in the cortex (but not the hippocampus) of cotinine-treated $\mathrm{Tg}$ mice relative to control $\mathrm{Tg}$ mice $(-26 \%, p=0.031)$. However, for both brain areas, no differences were observed for soluble levels of $A \beta_{42}$ and $A \beta_{40}$ in the cotininetreated $\mathrm{Tg}$ mice when compared with untreated $\mathrm{Tg}$ 

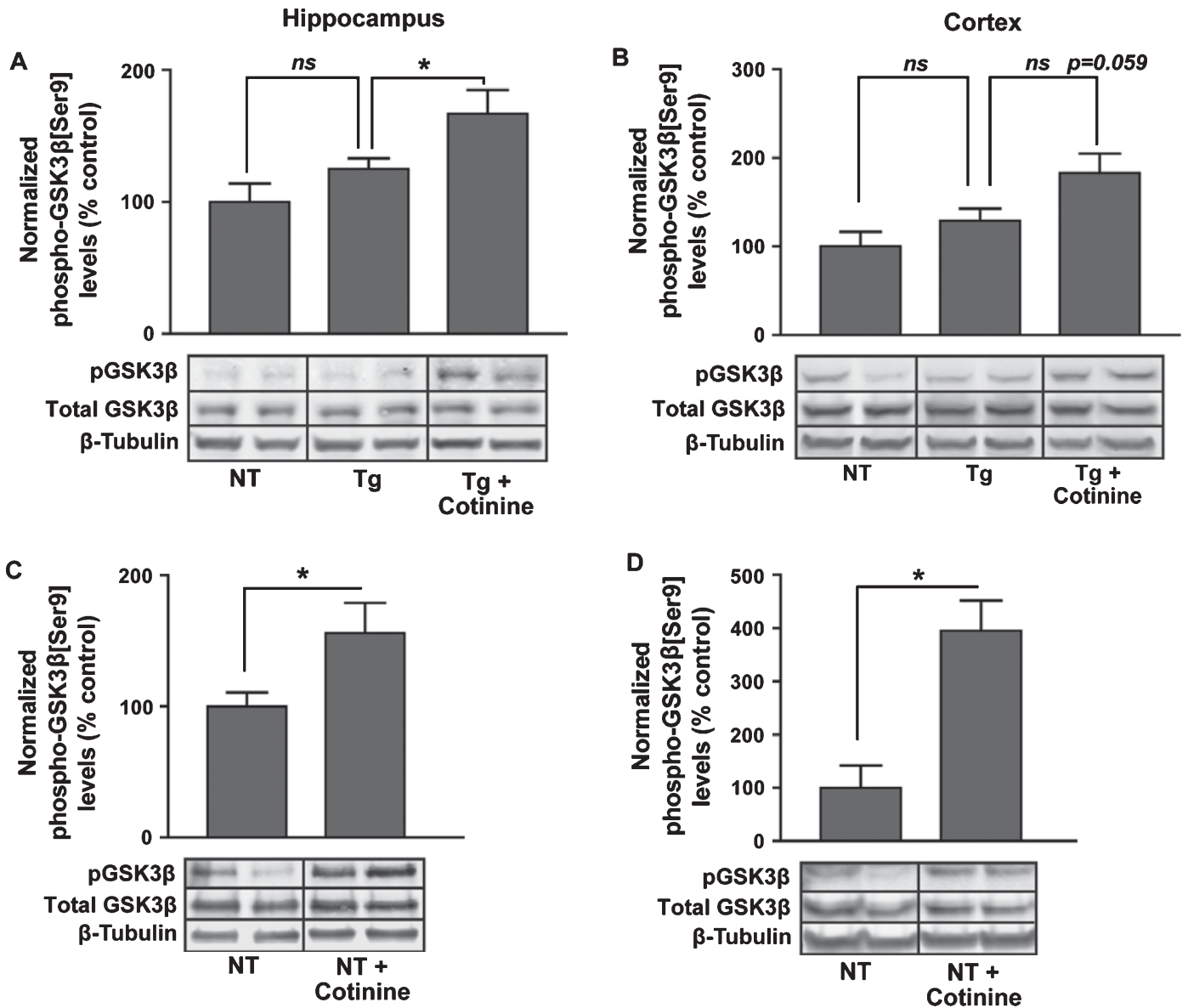

Fig. 3. Cotinine inhibits GSK3 $\beta$ by phosphorylation at serine 9 in the brains of Tg6799 and non-transgenic (NT) control littermate mice. Mice were treated with saline or cotinine $(2.5 \mathrm{mg} / \mathrm{kg})$ for 5 months and RIPA-soluble hippocampal and cortical extracts were analyzed by Western blot using antibodies against $\beta$-tubulin as well as total and phosphorylated GSK3 $\beta$. The plots represent the levels of immunoreactivity for phospho-GSK3 $\beta$ [Ser9] expressed as percentage of the saline-treated NT mice and normalized to total GSK3 $\beta$ levels. Levels of phosphoGSK3 $\beta$ [Ser9], total GSK3 $\beta$, and $\beta$-tubulin in the hippocampus (A, C) and cortex (B, D) of Tg and NT mice are shown. Cotinine increased the levels of phospho-GSK3 $\beta$ [Ser9] in the hippocampus of both Tg $(n=8-10)$ and NT mice $(n=8-10)($ A, C), as well as in the cortex of NT mice $(n=4-6)(D)$. After the cotinine treatment, the levels of phospho-GSK3 $\beta$ [Ser9] also showed a trend of increase $(p=0.059)$ in the cortex of Tg mice $(n=8-9)$ (B). Dividing lines separate immunoreactive bands from different parts of the same membrane. The data are expressed as the mean \pm SEM. Student's $t$-test was used to compare the mean of the values between groups. ${ }^{*} p<0.05$; pGSK3 $\beta$, phospho-GSK3 $\beta$ [Ser9].

Table 1

ELISA analysis of the levels of RIPA-soluble and insoluble A $\beta$ in the cortex and hippocampus of Tg6799 mice

\begin{tabular}{|c|c|c|c|c|c|c|}
\hline & \multicolumn{3}{|c|}{ Soluble (pg/mg) } & \multicolumn{3}{|c|}{ Insoluble (ng/mg) } \\
\hline & $\mathrm{A} \beta_{42}$ & $\mathrm{~A} \beta_{40}$ & $\mathrm{~A} \beta_{42} / \mathrm{A} \beta_{40}$ & $\mathrm{~A} \beta_{42}$ & $\mathrm{~A} \beta_{40}$ & $\mathrm{~A} \beta_{42} / \mathrm{A} \beta_{40}$ \\
\hline \multicolumn{7}{|l|}{ Cortex } \\
\hline Vehicle control & $249 \pm 54$ & $6 \pm 1$ & $41 \pm 5$ & $511 \pm 49$ & $84 \pm 13$ & $6.5 \pm 0.4$ \\
\hline Cotinine & $222 \pm 46$ & $7 \pm 1$ & $31 \pm 5$ & $364 \pm 40^{*}$ & $82 \pm 14$ & $4.9 \pm 0.3 * *$ \\
\hline \multicolumn{7}{|l|}{ Hippocampus } \\
\hline Vehicle control & $5829 \pm 988$ & $35 \pm 8$ & $204 \pm 57$ & $178 \pm 22$ & $34 \pm 3$ & $5.3 \pm 0.4$ \\
\hline Cotinine & $6942 \pm 718$ & $37 \pm 5$ & $194 \pm 18$ & $202 \pm 29$ & $54 \pm 6^{*}$ & $3.8 \pm 0.4^{*}$ \\
\hline
\end{tabular}

The data are expressed as the mean \pm SEM from 8-10 mice for the insoluble levels and 5-10 for soluble levels of the A $\beta$ peptides. Student's $t$-test was used to compare the mean of the values between groups. * $p<0.05 ; * * p<0.01$. 
mice. Although no differences in the levels of insoluble $A \beta_{40}$ were observed in the cortex, they showed a significant increase $(+31 \%, p=0.019)$ in the hippocampus of cotinine-treated $\mathrm{Tg}$ mice relative to $\mathrm{Tg}$ controls. The insoluble ratio of $A \beta_{42 / 40}$ was decreased by cotinine treatment in the cortex $(-25 \%, p=0.006)$ and hippocampus $(-28 \%, p=0.030)$. No significant changes were observed in the soluble ratio of $A \beta_{42 / 40}$ in these same brain regions.

\section{Effect of cotinine on amyloid burden in the brains of Tg6799 mice}

As expected from previous reports [54, 55], cotinine crossed the blood-brain barrier as evidenced using ELISA analysis of cotinine levels in the brain tissues. On average, the levels of cotinine in the RIPA-soluble fraction of the cortex of the NT and Tg mice fluctuated between 500 and $700 \mathrm{ng} / \mathrm{mg}$ protein.

To investigate whether the cotinine treatment reduces amyloid plaque deposition, Tg mice were evaluated for forebrain $A \beta$ burden at 7 months of age (following completion of behavioral testing). Tg6799 mice present $\mathrm{A} \beta$ deposition detectable as early as 2 months of age, which steadily increases through 8 months of age [25]. As shown in Fig. 4, control Tg mice had robust amyloid burdens of around 3\% in both cingulate and motor cortices. Compared to these $\mathrm{Tg}$ controls, $\mathrm{Tg}$ mice that had been given 5 months of cotinine treatment exhibited a significant decrease in amyloid burden within both cingulate cortex $(-26 \%$, $p=0.034)$ and motor cortex $(-17 \%, p=0.048)($ Fig. 4A and $\mathrm{B}$, respectively).

\section{Effect of cotinine on the levels of $A \beta$ oligomers in the hippocampus and cortex of Tg6799 mice}

Growing evidence supports the view that $A \beta$ oligomers are the main neurotoxic form of the peptide $[56,57]$. Thus, we investigated whether cotinine affected the levels of $A \beta$ oligomers in the brains of the $\mathrm{Tg}$ mice, using the highly specific anti-oligomeric $A \beta$ antibody A11, which does not recognize $A \beta$ monomers or $\mathrm{A} \beta \mathrm{PP}$. The results indicate that cotinine induced an $18-20 \%$ reduction in the immunoreactivity for A11 in the hippocampus (Fig. 5A and B) and cortex (data not shown) of $\mathrm{Tg}$ mice. No significant differences in 6E10 immunoreactivity were found between cotinine-treated $\mathrm{Tg}$ mice and $\mathrm{Tg}$ controls in both the hippocampus and cortex (data not shown).
A
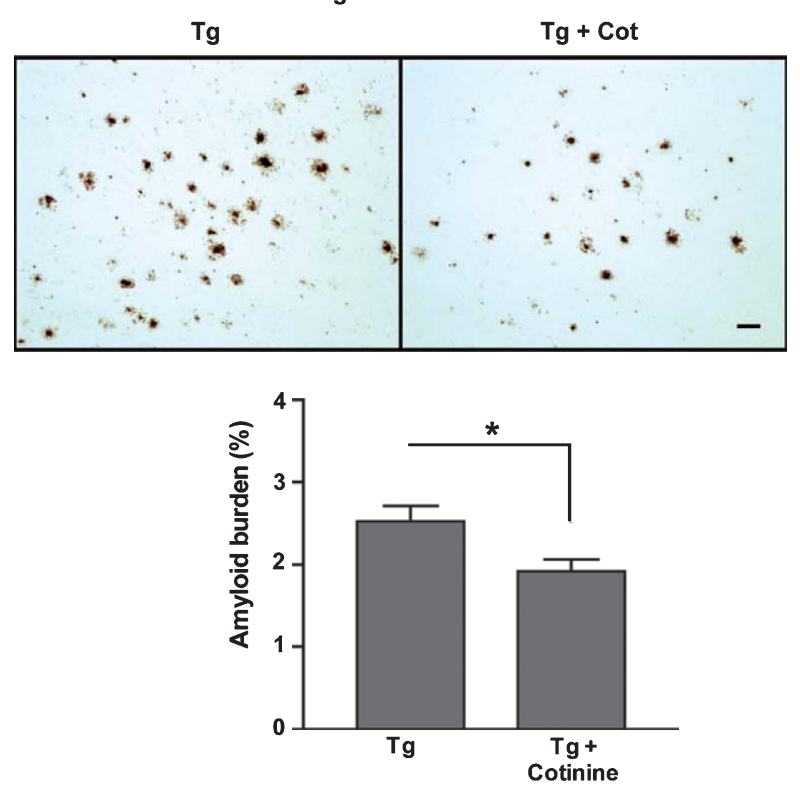

B
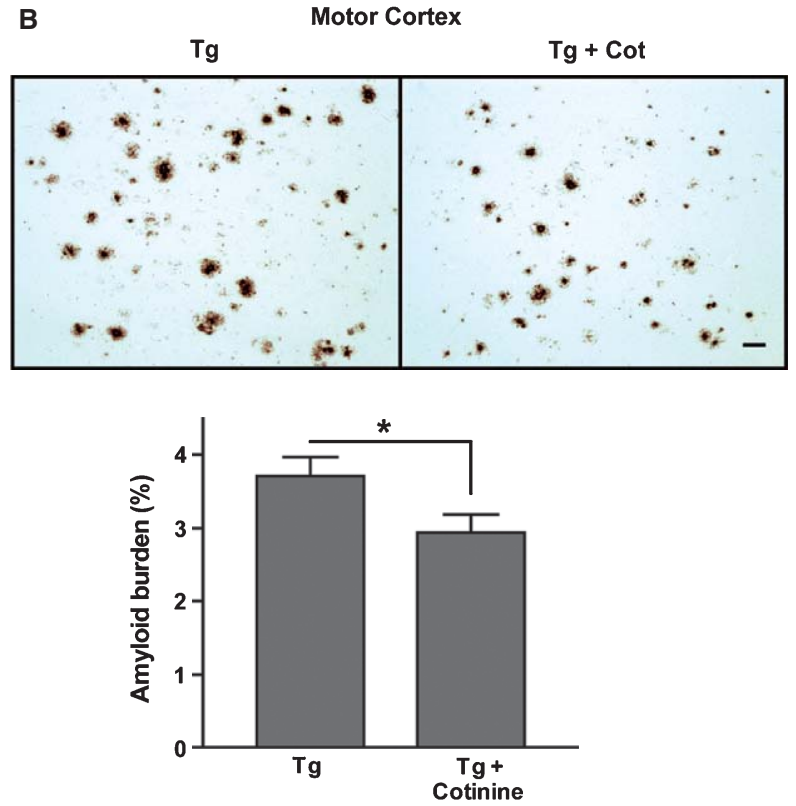

Fig. 4. Cotinine reduces amyloid burden in the cingulate and motor cortex of Tg6799 mice. Tg mice treated with cotinine showed less amyloid burden in the cortex compared to those without cotinine treatment. The photomicrographs are representative views of the amyloid plaques in the cingulate (A) and motor cortex (B) of brain sections of untreated and cotinine-treated mice $(n=9-11)$ stained with the A $\beta$-specific antibody 4G8. Scale bar $=50 \mu \mathrm{m}$. The graphs at the bottom represent the percentage of amyloid burden in these brain regions. The data are expressed as the mean \pm SEM. The Mann-Whitney rank sum test or the Student's $t$-test was used to compare the effects of cotinine treatment on amyloid burden quantified in both brain areas. ${ }^{*} p<0.05$. 
A
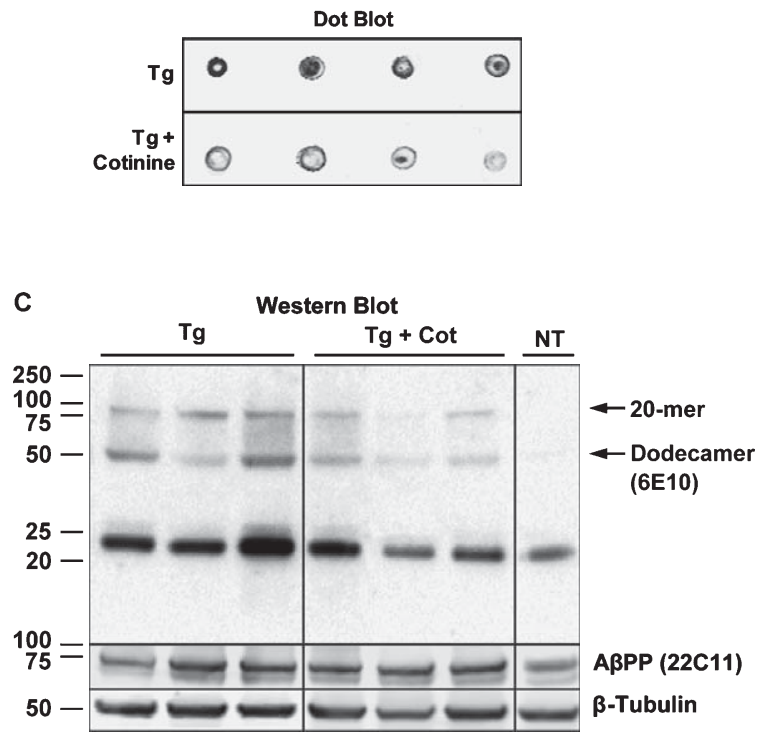
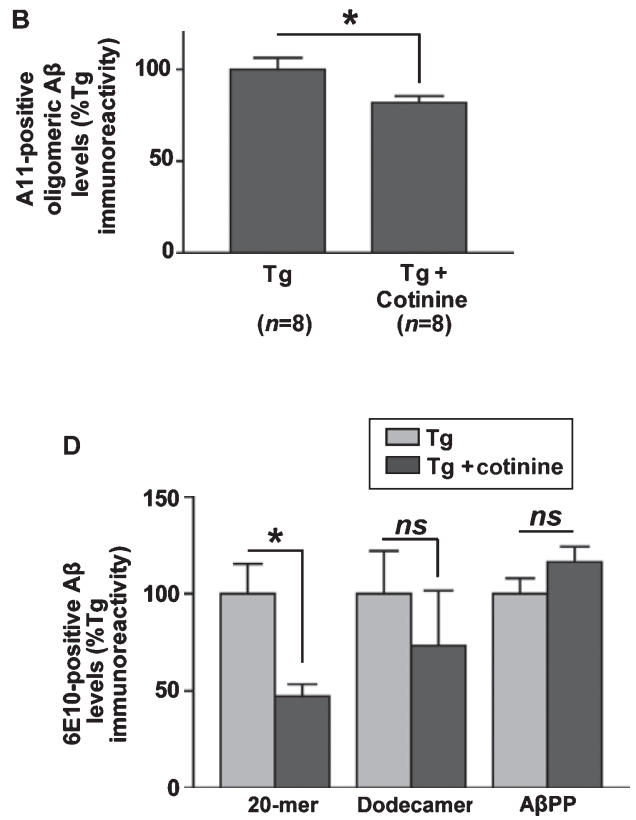

Fig. 5. Effect of Cotinine on A $\beta$ oligomers in the hippocampus of Tg6799 mice. The levels of A $\beta$ oligomers were analyzed in RIPA-soluble fractions of the hippocampus of vehicle-treated $(n=7)$ and cotinine-treated $(n=6) \mathrm{Tg}$ mice by dot blot and Western blot analysis. Representative images (A) and the graph (B) of the dot blot analysis are shown depicting the relative intensities of anti-oligomeric A $\beta$ (A11) immunoreactivity. Western blot image $(C)$ of the A $\beta$ oligomers and total A $\beta P P$ detected in hippocampal extracts of Tg and NT mice are shown, as analyzed using the antibodies $6 \mathrm{E} 10$ and 22C11, respectively. The densitometric analysis (D) showed that cotinine treatment significantly decreased the levels of high molecular weight 20-mer $\mathrm{A} \beta$ oligomers in the hippocampus of the Tg mice $(n=4-5)$. No significant changes were observed in $\beta$-tubulin or A $\beta$ PP levels. The data are expressed as the mean \pm SEM. Student's $t$-test was used to compare the mean of the values between groups. $* p<0.05$.

Furthermore, Western blot analyses of the RIPAsoluble fractions from $\mathrm{Tg}$ mice untreated or treated with cotinine $(2.5 \mathrm{mg} / \mathrm{kg})$ showed a reduction in the levels of soluble $\mathrm{A} \beta$ oligomers (Fig. $5 \mathrm{C}$ and D). We found a significant reduction in the levels of high molecular weight oligomers (i.e., 20-mers) $(-53 \%$, $p=0.018$ ) (Fig. 5C and D). No changes in the levels of low molecular weight oligomers $(<50 \mathrm{kDa})$ (Fig. 5C and $\mathrm{D}$ ) or the levels of $\mathrm{A} \beta \mathrm{PP}$ induced by cotinine were observed in the hippocampus of $\mathrm{Tg}$ mice as determined with the antibodies directed against $\mathrm{A} \beta$ (6E10) and total A $\beta P P(22 \mathrm{C} 11)$, respectively (Fig. 5C and D).

\section{Effect of cotinine on A $\beta$ aggregation}

To investigate whether cotinine affects fibril formation, we used AFM to analyze $A \beta$ aggregation in the presence and absence of cotinine. The solutions were prepared by dissolving $A \beta$ in HFIP and after evaporation, in PBS alone or containing cotinine, then incubated at $37^{\circ} \mathrm{C}$ for 10 days.

Figure 6 shows representative AFM images $(900 \times$ $900 \mathrm{~nm}$ field) of aggregated forms of $A \beta$ formed in either the absence (Fig. 6A and B) or presence (Fig. 6C) of cotinine. The analysis of $A \beta$ fibril formation at day
0 showed no presence of aggregated $A \beta$ in the initial solutions (Fig. 6A). After 10 days of incubation at $37^{\circ} \mathrm{C}$, the height of the $\mathrm{A} \beta_{42}$ aggregates used for the AFM studies fluctuated approximately between 1 and $15 \mathrm{~nm}$ (data not shown), indicating that the solutions contained a mixture of oligomers, protofibrils, and fibrils. The pre-incubation of the peptide in the presence of cotinine significantly reduced the length of $A \beta$ fibrils. The average length of $A \beta$ fibrils incubated in the presence of cotinine was significantly lower $(239 \pm 34 \mathrm{~nm})$ than the average fibril length in the absence of cotinine ( $486 \pm 157 \mathrm{~nm}$, Student's $t$ test, $p=0.026)$ (Fig. 6D).

\section{Molecular modeling of cotinine $-A \beta_{1-42}$ interaction}

A previous analysis of the interaction of $A \beta$ with nicotine by NMR preceded and facilitated the molecular modeling of cotinine [42, 43]. These NMR studies suggested that nicotine binds to the segment of $\mathrm{A} \beta$ between amino acids 1-28 when folded in an $\alpha$-helical conformation. According to the proposed mechanism, nicotine inhibits the conformational change from $\alpha$-helix to the amyloidogenic $\beta$-sheet conformation 
A

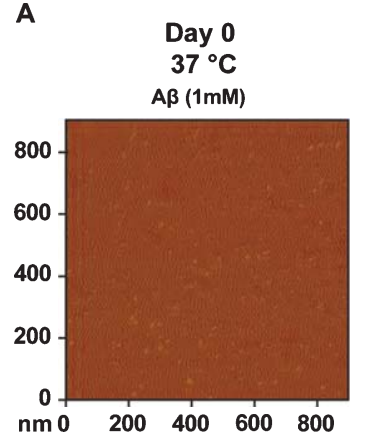

B

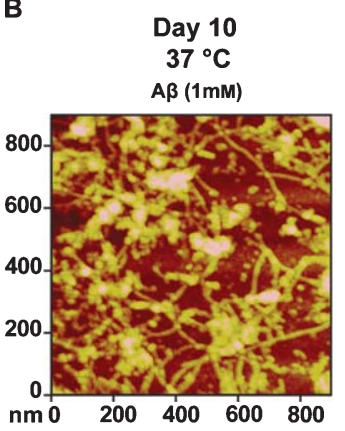

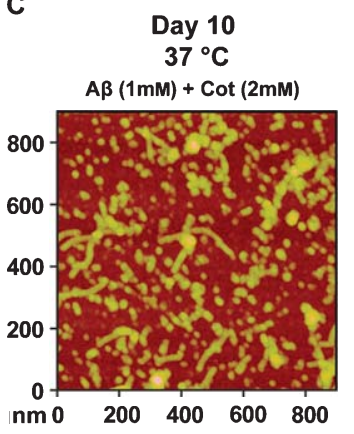

D

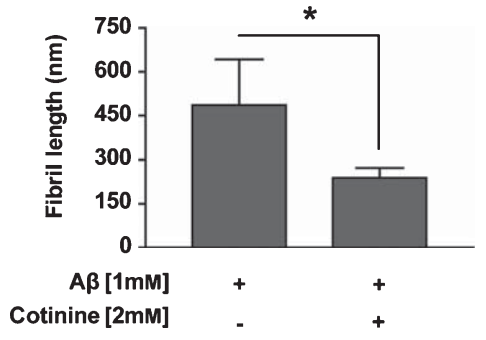

Fig. 6. Atomic force microscopy (AFM) analysis of the effect of cotinine on $A \beta_{1-42}$ fibrillation. A $900 \mathrm{~nm}$ field of AFM analysis of A $\beta_{1-42}$ peptide solutions $(1 \mathrm{mM})$ incubated for 10 days at $37^{\circ} \mathrm{C}$ in the absence $(\mathrm{A}$ and $\mathrm{B}$ ) or presence of cotinine $2 \mathrm{mM}(\mathrm{C})$. A. represents the analysis of fibrils at time zero. At 10 days of incubation (B) some long $A \beta_{1-42}$ fibrils, few short linear protofibrils, and a heterogeneous mix of large globular aggregates were observed when the solutions were incubated in absence of cotinine. In the presence of cotinine (C) there was an evident decrease in the size and length of the peptide aggregates. The difference in length of the $A \beta_{1-42}$ fibrils under these conditions were significant with $p=0.026$ (Student's $t$-test) (D). The differences in length of A $\beta$ fibrils expressed as mean values \pm SEM were considered significant: $* p<0.05$.

[42]. Here, we used molecular modeling to analyze the interaction of cotinine with $A \beta_{1-42}$ and define a putative mechanism that could explain the effect of cotinine on $A \beta$ aggregation. The RMSD of the MD simulation confirmed that the complex is thermodynamically equilibrated only after $30 \mathrm{~ns}$ (Fig. 7A). The most representative structure derived from the simulation indicates that cotinine interacts with His6, Tyr10, and His14 residues of the $A \beta_{1-42}$ peptide (Fig. 7B). As shown in the figure, the pyridine ring of cotinine is positioned between the imidazole ring of His6 and the phenyl ring of Tyr10. It interacts with these residues through strong $\pi-\pi$ interactions that are indicated by the distances of $4.3 \AA$ and 4.1 A between cotinine-His6 and cotinine-Tyr10 aromatic rings, respectively. In the equilibrated region, the distance between the center of the aromatic ring of Tyr 10 and the pyridine ring of cotinine remains around $4.0 \AA$ (Fig. 7C). On the other hand, cotinine interacts with His14 via $\mathrm{C}-\mathrm{H}-\pi$ interaction [(cotinine-C)-H-His $14=3.2 \AA]$. As discussed below, the interactions of cotinine with His6, Tyr10, and His 14 residues of $A \beta_{1-42}$ introduce significant changes in the secondary structure of the peptide (Fig. 7D).

In the free $A \beta_{1-42}$ peptide, in the first $38 \mathrm{~ns}$, the Phe20-Val24 region is dominated by bend-andturn conformations with sporadic helical structures (Fig. 7D, top). It is then transformed into bend and coil structures. However, in the cotinine-bound structure, for the first $25 \mathrm{~ns}$ this region exists in helical conformation but it is later converted into the stable turn structure (shown by the yellow color in Fig. 7D, bottom). In the free peptide, the loop region (24-28, VGSNK) is quite unstable and undergoes a large dynamical trans- formation between bend and turn. In the presence of cotinine, in a marked difference, initially (for the first $22 \mathrm{~ns}$ ) this segment exists in the helical form but later it adopts stable bend and coil conformations. The second hydrophobic domain (29-35, GAIIGLM) in free $\mathrm{A} \beta_{1-42}$ is dominated by the bend structure for the first $28 \mathrm{~ns}$ but after that it is converted into a turn with a partial $\beta$-sheet character. On the other hand, in the cotinine-bound structure, the Gly29-Ile32 fragment of this region stays in the stable helical form throughout the simulation. The remaining Leu33-Met35 segment, after $28 \mathrm{~ns}$, is transformed into the stable bend conformation.

\section{DISCUSSION}

The progressive deterioration of working memory is one of the main characteristics of $\mathrm{AD}$, and effective therapies targeting memory loss in $\mathrm{AD}$ have been elusive. Here, we investigated the actions of cotinine as an anti-A $\beta$ aggregation and memory-enhancing agent. More specifically, we studied the effect of cotinine on the deterioration of cognitive abilities, plaque formation, $A \beta$ aggregation, and the activation of Akt/GSK3 $\beta$ pathway in the brains of the Tg6799 mice. We found that chronic treatment with cotinine improved working and reference memories and reduced both $A \beta_{1-42}$ oligomerization and plaque burden in Tg6799 mice. Furthermore, we found that cotinine stimulated the activation of Akt and the inhibition of GSK3 $\beta$ by phosphorylation in the hippocampus and cortex of both Tg and NT littermate mice. We also discovered that 

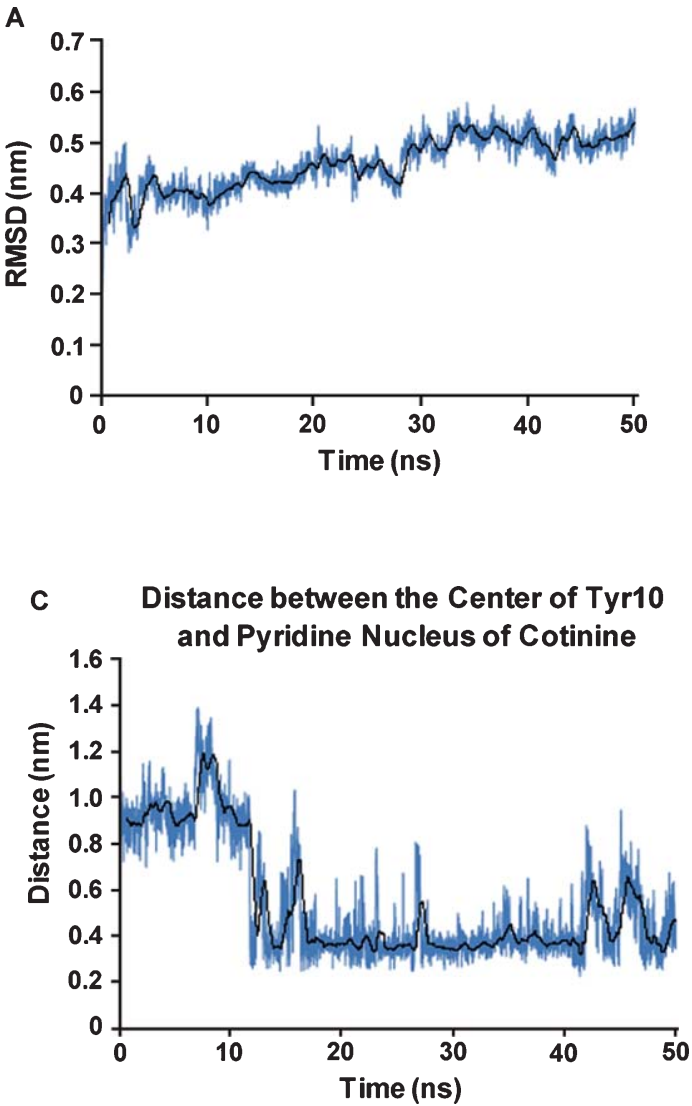

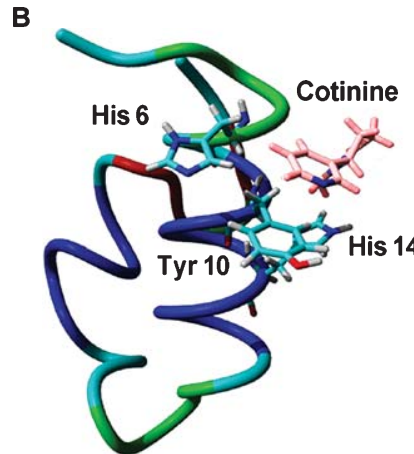

(1)

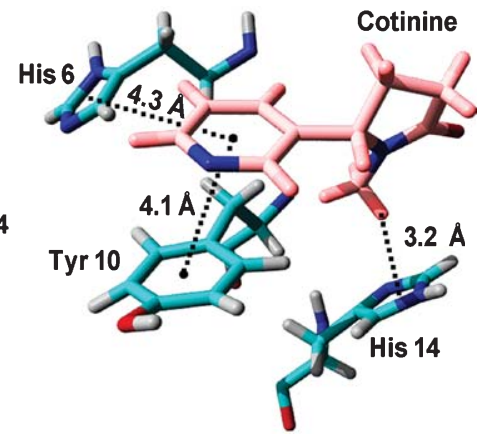

(2)

D
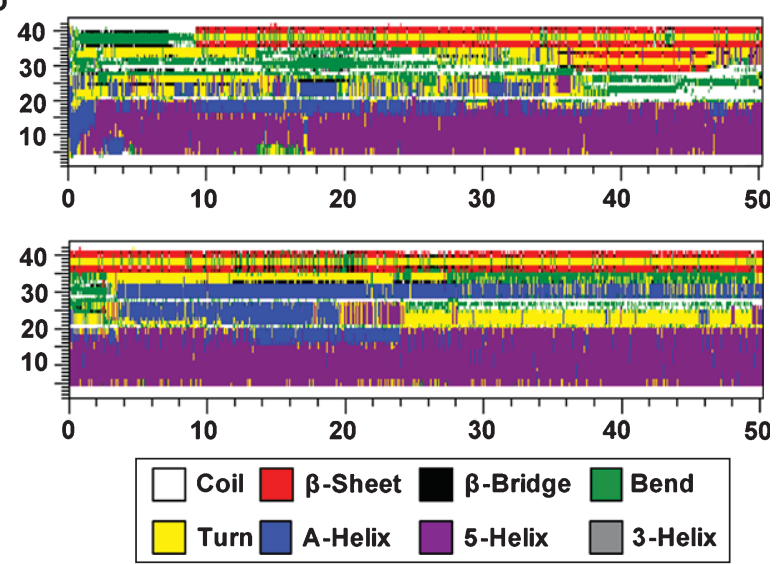

Fig. 7. Cotinine interacts with key residues of $A \beta_{1-42}$ involved in its aggregation. Root-mean-square-deviations (RMSD) plotted against time for the molecular dynamics (MD) trajectory of cotinine-A $\beta_{1-42}$ complex $(A)$. The most representative structure derived from the 50 ns $\mathrm{MD}$ simulation on cotinine-A $\beta_{1-42}$ complex with specific interactions of cotinine (shown in pink) at the $A \beta_{1-42}$ binding site (B1 and $B 2$ ). Distance between the center of Tyr10 and pyridine nucleus of cotinine with the numbers representing the distances in $\AA$ (C). Secondary structural assignment per residue as a function of time: For the free $A \beta_{1-42}$ monomer $\left(D\right.$, top) and the cotinine-A $\beta_{1-42}$ complex (D, bottom).

cotinine inhibited $A \beta_{1-42}$ aggregation into oligomers and fibrils in vitro. Furthermore, using MD we modeled the cotinine-A $\beta_{1-42}$ interaction and elucidated a mechanism by which cotinine may interfere with $A \beta$ aggregation.

In the search for new therapeutic agents against $\mathrm{AD}$, cotinine, the main metabolite of nicotine, attracted our attention due to its unique pharmacological characteristics and safety profile. Specifically, cotinine is a poor agonist of the nAChRs [20-22], crosses the blood-brain barrier [54], is much less prone to induce respiratory arrest than nicotine, and has minimal toxic side-effects in humans $[23,58,59]$. We found that long-term treatment of $\operatorname{Tg} 6799$ mice with cotinine beginning in young adulthood ( 2 months of age) protected their cognitive abilities in multiple tasks and cognitive domains when tested between 5.5 and
6.5 months of age. It has been reported that at the age we started cotinine treatment, senile plaques in Tg6799 mice are beginning to appear with a large increase occurring thereafter. Thus, it is likely that our mice have no plaques or were at early stages of plaque formation when the treatment started. Regarding behavioral characterization of the Tg6799 mice, this group reported initial cognitive impairment (in Y-maze and Morris maze acquisition/retention) to occur at 4-6 months of age $[25,26]$, with impairment in trace fear conditioning present by 5-6 months of age [26, 27].

In the present study, we found several cognitive domains that were impaired in $\operatorname{Tg} 6799$ mice between 5.5 and 6.5 months of age. In the tasks testing reference (circular platform) and working learning and memory (RAWM, cognitive interference), treatment with 
cotinine administered from early adulthood provided significant protection against otherwise certain cognitive impairment. We did not observe changes in the Morris maze likely due to the lower sensitivity of this test to detect cognitive changes in $\mathrm{AD}$ mice. The tasks wherein cotinine did enhance performance are more sensitive tasks (i.e., radial arm water maze, cognitive interference task) and/or analyze different cognitive abilities (circular platform). Indeed, we have previously reported that on AD therapeutics some drugs have effects in these tasks without being effective in the Morris water maze [60].

Overall, we hypothesize that cotinine may be useful in preventing cognitive deterioration when administered to individuals not yet exhibiting $\mathrm{AD}$ cognitive impairment or those with mild cognitive impairment at early stages of the disease.

Consistent with a positive effect of cotinine on brain homeostasis and function, we have found that cotinine treatment stimulated Akt in the hippocampus and cortex of both Tg and NT mice. The multiple effects of the activation of Akt in the brain, including the enhancement of brain plasticity and neuronal survival as well as the inhibition of GSK3 $\beta$, may be critical to mediate the positive effect of cotinine on memory [61].

GSK $3 \beta$ is a proline-directed serine/threonine kinase considered to be a key protein in both sporadic and genetic forms of AD. According to this view, the over-activation of GSK3 $\beta$ leads to an increase in A $\beta$ production, tau hyperphosphorylation, neuroinflammation, and consequently memory impairment [62].

Hyperphosphorylated tau is the main component of paired-helical filaments forming the neurofibrillary tangles (NFT), one of the main pathological hallmarks in AD brains. GSK3 $\beta$ phosphorylates tau at several sites [63] and its levels positively correlate with the presence of NFT in AD brains [64]. Furthermore, the over-expression of GSK $3 \beta$ in forebrain regions is associated with neurodegeneration [53]. Interestingly, the activation of the Akt/GSK3 pathway is also induced by other drugs currently used for the treatment of $\mathrm{AD}$ such as physostigmine and memantine [30].

We also investigated the effect of long-term cotinine treatment on plaque deposition in Tg6799 mice. Treatment with cotinine significantly reduced the extent of $\mathrm{A} \beta$ deposition into plaques in the cingulate and motor cortices and the levels of insoluble $A \beta_{42}$ in the cortex. This decrease in $A \beta$ deposition was most likely the result of a reduction in $A \beta$ aggregation, although an enhancement of $A \beta$ clearance by cotinine as an additional mechanism cannot be ruled out at the present time.
More importantly, we observed that cotinine treatment induced a clear decrease in the ratio $A \beta_{42} / A \beta_{40}$ in the hippocampus and cortex of transgenic mice. The decrease in the $A \beta_{42} / A \beta_{40}$ ratio can explain at least in part its beneficial actions, as this ratio has been shown to be important for the development of $\mathrm{AD}$, by determining the fibrillogenesis and toxicity of $A \beta[65,66]$. For example, it has been reported that $A \beta_{40}$ affects the $A \beta_{42}$ fibrillation, decreasing its conversion to mature fibrils [65]. In another study, it was found that the age-of-onset of the pathology in individuals carrying PS1-linked FAD mutations inversely correlated with $A \beta_{42} / A \beta_{40}$ and absolute levels of $A \beta_{42}$, but directly with $A \beta_{40}$ levels [67]. Furthermore, clinical studies have demonstrated that this ratio can also determine the distribution of $A \beta$ (i.e., parenchymal or vascular $A \beta$ deposition) in $\mathrm{AD}$ brains $[60,68]$. Coherent with these previous findings, in conjunction with a decrease in the $A \beta_{42} / A \beta_{40}$ ratio we observed an increase in insoluble $A \beta_{40}$ in the hippocampus of cotinine-treated $\mathrm{Tg}$ mice, which can have a further beneficial effect in inhibiting $\mathrm{A} \beta_{42}$ fibrillation.

Cotinine did not change the total levels of soluble $\mathrm{A} \beta$ peptides. However, it decreased the levels of $A \beta$ oligomers in the brains of the transgenic mice. Two other potential therapeutics, which suppress $A \beta$ aggregation and also provide clear cognitive benefit to $\mathrm{AD}$ $\mathrm{Tg}$ mice, such as melatonin and electromagnetic fields, reduced deposited/insoluble $A \beta$ without affecting the soluble $A \beta$ [69]. These studies, along with our present findings, suggest that a small reduction in oligomers without changes in total $A \beta$ levels may be enough to attain cognitive benefits in affected individuals.

The soluble aggregated forms of $A \beta$, including oligomers and protofibrils, have been proposed as the main pathological species in AD brains, as their accumulation is sufficient to induce synaptic and cognitive deficits in vivo $[2,57,70-74]$. The aggregation of $A \beta$ is required for its toxicity; in fact, a physiological function for the monomeric form of the peptide stimulating synaptic plasticity has been suggested $[39,75]$. Thus, compared to other therapeutic approaches, a distinct advantage of anti-A $\beta$ aggregation agents like cotinine is that they can target the toxic forms of $\mathrm{A} \beta$ without disrupting a possible normal function of the monomeric form of the peptides.

To investigate whether the cotinine-induced reduction of $A \beta$ aggregates in the brain was at least in part due to an inhibition of the peptide aggregation, we examined the effect of cotinine on $A \beta$ aggregation in vitro. It was previously shown using NMR and circular dichroism techniques in vitro that cotinine binds 
to $A \beta$ with high affinity, inhibiting its aggregation into fibrils $[42,75,76]$. Using X-ray fiber diffraction, we have previously found evidence suggesting that cotinine may reduce the extent of hydrogen-bonding and fiber growth for the fibrillogenic peptide $A \beta_{12-28}$ [77].

Thus, we studied the effect of cotinine on $A \beta_{1-42}$ aggregation using AFM. Previous studies showed that in vitro $\mathrm{A} \beta$ monomers can associate into soluble high molecular weight (HMW) oligomers with a diameter between 15 and $25 \mathrm{~nm}$, which after further aggregation transform into structures of greater dimensions. It has been reported that for $A \beta$ oligomers, the average height is $2-5 \mathrm{~nm}[39,75]$ and for fibrils, the height fluctuates between 3 and $9 \mathrm{~nm}[75,76]$. The analysis of the height of the $A \beta_{42}$ aggregates indicated that the fibrillation mixtures contained a heterogeneous mix of oligomeric, protofibrillar, and fibrillar forms of the peptide.

Notably, even under extreme conditions that promoted fibrillation such as high concentrations of $A \beta$, high temperature, and long-incubation time, cotinine inhibited the growth of $A \beta$ fibrils as evidenced by the significant decrease in the average length of the $A \beta$ aggregates. Overall, these findings support the view that the reduction in $A \beta$ oligomers and plaques in the brains of cotinine-treated $\mathrm{Tg}$ mice was the result of an inhibition of $A \beta$ aggregation.

The effect of cotinine over $A \beta$ aggregation may be explained by the nature of the molecular interaction of cotinine with the peptide. The analysis of MD simulations of cotinine-A $\beta_{1-42}$ interactions suggests that in the thermodynamically-equilibrated region, cotinine may interact with His6, Tyr10, and His14 residues of the $A \beta_{1-42}$ peptide, with His6 and Tyr10 residues through $\pi-\pi$ interactions and with His14 via $\mathrm{C}-\mathrm{H}-\pi$ interaction. The interaction of cotinine with these residues introduced significant changes in the secondary structure of $A \beta_{1-42}$.

According to the data, the cotinine-bound structure is different from the free form of the $A \beta_{1-42}$ peptide. The secondary structural analysis of MD simulations also showed that the interaction with cotinine significantly influences the Phe20-Met35 region of the full-length monomeric form of the $A \beta_{1-42}$ peptide. This segment contains both the loop (24-28, VGSNK) and the second hydrophobic domain (29-35, GAIIGLM) regions, which have been proposed to play important roles in the aggregation process [78]. It is noteworthy that the binding of cotinine does not affect the stable helical conformation of its immediate binding site (His6, Tyr10, and His14 residues containing the Asp1-Phe19 region). Altogether, these results suggest that cotinine binds to $A \beta_{1-42}$, inducing important structural changes that may play a critical role in inhibiting aggregation of the peptide.

The investigation of compounds that inhibit $A \beta$ aggregation has shown that numerous compounds affect A $\beta$ fibrillation [38], with a small number of compounds affecting oligomerization such as, $\beta$-cyclodextrin derivatives [79], curcumin [80], Ginkgo biloba [81], and $o$-vanillin [82]. From the agents that inhibit $\mathrm{A} \beta$ oligomerization, few (e.g., Ginkgo biloba) have been tested in vivo [83, 84].

To our best knowledge, this study provides the first evidence that cotinine reduces $\mathrm{A} \beta$ aggregation in the brain, prevents memory loss, and stimulates the Akt/GSK3 $\beta$ pathway in vivo. Thus, the multiple-action drug cotinine has therapeutic benefits against AD-like pathology in an animal model of the disease. The unique pharmacological properties, including its good safety profile in humans, makes cotinine an attractive candidate for the treatment of $\mathrm{AD}$.

\section{ACKNOWLEDGMENTS}

This material is the result of work supported with resources and the use of facilities at the Bay Pines VA Healthcare System and the James A. Haley Veterans' Hospital. The contents do not represent the views of the Department of Veterans Affairs or the United States Government. The authors thank Professor Wenzhi Li (Department of Physics, Florida International University, Miami, FL) for permission to use his AFM equipment and for technical help in the AFM measurements. Also, we thank Dr. Hugo Fernandez (Bay Pines Veterans Affairs Healthcare System, Bay Pines, FL) and the Bay Pines Foundation, Inc. for their constant support. This work was supported by grants from the James and Esther King Biomedical Research Program of the Florida Department of Health (DOH 07KN-04 to VE), a New Investigator Award from the Alzheimer's Association (to VE), the Johnnie B. Byrd, Sr., Florida Alzheimer's Disease Research Center (to VE), the Japan Society for the Promotion of Science (18500279 and 22500320, to TM), the Alzheimer's Association (to DAK), and Boston College Institutional Research Support Funds (to DAK). A funding grant (DOH grant number $08 \mathrm{KN}-11$ ) to RP from the James and Esther King Biomedical Research Program of the Florida Department of Health is acknowledged.

Authors' disclosures available online (http://www.jalz.com/disclosures/view.php?id=744). 


\section{REFERENCES}

[1] Lawrence AD, Sahakian BJ (1995) Alzheimer disease, attention, and the cholinergic system. Alzheimer Dis Assoc Disord 9(Suppl 2), 43-49.

[2] Echeverria V, Cuello AC (2002) Intracellular A-beta amyloid, a sign for worse things to come? Mol Neurobiol 26, 299-316.

[3] Hardy J, Selkoe DJ (2002) The amyloid hypothesis of Alzheimer's disease: progress and problems on the road to therapeutics. Science 297, 353-356.

[4] Nordberg A (2001) Nicotinic receptor abnormalities of Alzheimer's disease: therapeutic implications. Biol Psychiatry 49, 200-210.

[5] Mufson EJ, Counts SE, Perez SE, Ginsberg SD (2008) Cholinergic system during the progression of Alzheimer's disease: therapeutic implications. Expert Rev Neurother 8, 1703-1718.

[6] Tsuno N (2009) Donepezil in the treatment of patients with Alzheimer's disease. Expert Rev Neurother 9, 591-598.

[7] Nordberg A (2006) Mechanisms behind the neuroprotective actions of cholinesterase inhibitors in Alzheimer disease. Alzheimer Dis Assoc Disord 20, S12-S18.

[8] Bullock R (2002) The clinical benefits of rivastigmine may reflect its dual inhibitory mode of action: an hypothesis. Int $J$ Clin Pract 56, 206-214.

[9] Munoz-Torrero D (2008) Acetylcholinesterase inhibitors as disease-modifying therapies for Alzheimer's disease. Curr Med Chem 15, 2433-2455.

[10] Umegaki H, Itoh A, Suzuki Y, Nabeshima T (2008) Discontinuation of donepezil for the treatment of Alzheimer's disease in geriatric practice. Int Psychogeriatr 20, 800-806.

[11] Raina P, Santaguida P, Ismaila A, Patterson C, Cowan D, Levine M, Booker L, Oremus M (2008) Effectiveness of cholinesterase inhibitors and memantine for treating dementia: evidence review for a clinical practice guideline. Ann Intern Med 148, 379-397.

[12] Gongadze N, Antelava N, Kezeli T, Okudjava M, Pachkoria K (2008) The mechanisms of neurodegenerative processes and current pharmacotherapy of Alzheimer's disease. Georgian Med News, 44-48.

[13] Graves AB, van Duijn CM, Chandra V, Fratiglioni L, Heyman A, Jorm AF, Kokmen E, Kondo K, Mortimer JA, Rocca WA, et al. (1991) Alcohol and tobacco consumption as risk factors for Alzheimer's disease: a collaborative re-analysis of casecontrol studies. EURODEM Risk Factors Research Group. Int J Epidemiol 20(Suppl 2), S48-S57.

[14] Hellstrom-Lindahl E, Mousavi M, Ravid R, Nordberg A (2004) Reduced levels of Abeta 40 and Abeta 42 in brains of smoking controls and Alzheimer's patients. Neurobiol Dis 15, 351-360.

[15] Nordberg A, Hellstrom-Lindahl E, Lee M, Johnson M, Mousavi M, Hall R, Perry E, Bednar I, Court J (2002) Chronic nicotine treatment reduces beta-amyloidosis in the brain of a mouse model of Alzheimer's disease (APPsw). J Neurochem 81, 655-658.

[16] Karaconji IB (2005) Facts about nicotine toxicity. Arh Hig Rada Toksikol 56, 363-371.

[17] Carlson J, Noguchi K, Ellison G (2001) Nicotine produces selective degeneration in the medial habenula and fasciculus retroflexus. Brain Res 906, 127-134.

[18] Vaglenova J, Parameshwaran K, Suppiramaniam V, Breese CR, Pandiella N, Birru S (2008) Long-lasting teratogenic effects of nicotine on cognition: gender specificity and role of AMPA receptor function. Neurobiol Learn Mem 90, 527536.
[19] Terry AV Jr, Hernandez CM, Hohnadel EJ, Bouchard KP, Buccafusco JJ (2005) Cotinine, a neuroactive metabolite of nicotine: potential for treating disorders of impaired cognition. CNS Drug Rev 11, 229-252.

[20] Briggs CA, McKenna DG (1998) Activation and inhibition of the human alpha7 nicotinic acetylcholine receptor by agonists. Neuropharmacology 37, 1095-1102.

[21] Briggs CA, McKenna DG, Monteggia LM, Touma E, Roch JM, Arneric SP, Gopalakrishnan M, Sullivan JP (1999) Gain of function mutation of the alpha7 nicotinic receptor: distinct pharmacology of the human alpha7 V274T variant. Eur J Pharmacol 366, 301-308.

[22] Vainio PJ, Tuominen RK (2001) Cotinine binding to nicotinic acetylcholine receptors in bovine chromaffin cell and rat brain membranes. Nicotine Tob Res 3, 177-182.

[23] Hatsukami D, Pentel PR, Jensen J, Nelson D, Allen SS, Goldman A, Rafael D (1998) Cotinine: effects with and without nicotine. Psychopharmacology (Berl) 135, 141-150.

[24] Benowitz NL, Kuyt F, Jacob P 3rd, Jones RT, Osman AL (1983) Cotinine disposition and effects. Clin Pharmacol Ther 34, 604-611.

[25] Oakley H, Cole SL, Logan S, Maus E, Shao P, Craft J, Guillozet-Bongaarts A, Ohno M, Disterhoft J, Van Eldik L, Berry R, Vassar R (2006) Intraneuronal beta-amyloid aggregates, neurodegeneration, and neuron loss in transgenic mice with five familial Alzheimer's disease mutations: potential factors in amyloid plaque formation. J Neurosci 26, 1012910140.

[26] Ohno M, Chang L, Tseng W, Oakley H, Citron M, Klein WL, Vassar R, Disterhoft JF (2006) Temporal memory deficits in Alzheimer's mouse models: rescue by genetic deletion of BACE1. Eur J Neurosci 23, 251-260.

[27] Kaczorowski CC, Sametsky E, Shah S, Vassar R, Disterhoft JF (2009) Mechanisms underlying basal and learning-related intrinsic excitability in a mouse model of Alzheimer's disease. Neurobiol Aging. doi:10.1016/ j.neurobiolaging.2009.09.003

[28] Mizuno M, Yamada K, Takei N, Tran MH, He J, Nakajima A, Nawa H, Nabeshima T (2003) Phosphatidylinositol 3-kinase: a molecule mediating BDNF-dependent spatial memory formation. Mol Psychiatry 8, 217-224.

[29] Chong ZZ, Li F, Maiese K (2005) Activating Akt and the brain's resources to drive cellular survival and prevent inflammatory injury. Histol Histopathol 20, 299-315.

[30] de Sarno P, Bijur GN, Zmijewska AA, Li X, Jope RS (2006) In vivo regulation of GSK3 phosphorylation by cholinergic and NMDA receptors. Neurobiol Aging 27, 413422.

[31] Frame S, Cohen P, Biondi RM (2001) A common phosphate binding site explains the unique substrate specificity of GSK3 and its inactivation by phosphorylation. Mol Cell 7, 13211327.

[32] Arendash GW, Mori T, Cao C, Mamcarz M, Runfeldt M, Dickson A, Rezai-Zadeh K, Tan J, Citron BA, Lin X, Echeverria V, Potter H (2009) Caffeine reverses cognitive impairment and decreases brain Amyloid-beta levels in aged Alzheimer's disease mice. J Alzheimers Dis 17, 661-680.

[33] Echeverria V, Burgess S, Gamble-George J, Zeitlin R, Lin X, Cao C, Arendash GW (2009) Sorafenib inhibits nuclear factor kappa B, decreases inducible nitric oxide synthase and cyclooxygenase- 2 expression, and restores working memory in APPswe mice. Neuroscience 162, 1220-1231.

[34] Pompl PN, Mullan MJ, Bjugstad K, Arendash GW (1999) Adaptation of the circular platform spatial memory task for mice: use in detecting cognitive impairment in the APP(SW) 
transgenic mouse model for Alzheimer's disease. J Neurosci Methods 87, 87-95.

[35] Loewenstein DA, Acevedo A, Luis C, Crum T, Barker WW, Duara R (2004) Semantic interference deficits and the detection of mild Alzheimer's disease and mild cognitive impairment without dementia. J Int Neuropsychol Soc 10, 91-100.

[36] Tan J, Town T, Crawford F, Mori T, DelleDonne A, Crescentini R, Obregon D, Flavell RA, Mullan MJ (2002) Role of CD40 ligand in amyloidosis in transgenic Alzheimer's mice. Nat Neurosci 5, 1288-1293.

[37] Mori T, Town T, Tan J, Yada N, Horikoshi Y, Yamamoto J, Shimoda T, Kamanaka Y, Tateishi N, Asano T (2006) Arundic acid ameliorates cerebral amyloidosis and gliosis in Alzheimer transgenic mice. J Pharmacol Exp Ther 318, 571-578.

[38] Necula M, Kayed R, Milton S, Glabe CG (2007) Small molecule inhibitors of aggregation indicate that amyloid beta oligomerization and fibrillization pathways are independent and distinct. J Biol Chem 282, 10311-10324.

[39] Chromy BA, Nowak RJ, Lambert MP, Viola KL, Chang L, Velasco PT, Jones BW, Fernandez SJ, Lacor PN, Horowitz P, Finch CE, Krafft GA, Klein WL (2003) Self-assembly of Abeta(1-42) into globular neurotoxins. Biochemistry 42, 12749-12760.

[40] Morris GM, Goodsell DS, Halliday RS, Huey R, Hart WE, Belew RK, Olson AJ (1998) Automated docking using a lamarckian genetic algorithm and empirical binding free energy function. J Comp Chem 19, 1639-1662.

[41] Triguero L, Singh R, Prabhakar R (2008) Comparative molecular dynamics studies of wild-type and oxidized forms of full-length Alzheimer amyloid beta-peptides Abeta(1-40) and Abeta(1-42). J Phys Chem B 112, 7123-7131.

[42] Salomon AR, Marcinowski KJ, Friedland RP, Zagorski MG (1996) Nicotine inhibits amyloid formation by the betapeptide. Biochemistry 35, 13568-13578.

[43] Moore SA, Huckerby TN, Gibson GL, Fullwood NJ, Turnbull S, Tabner BJ, El-Agnaf OM, Allsop D (2004) Both the D-(+) and L-(-) enantiomers of nicotine inhibit Abeta aggregation and cytotoxicity. Biochemistry 43, 819-826.

[44] Ono K, Hasegawa K, Yamada M, Naiki H (2002) Nicotine breaks down preformed Alzheimer's beta-amyloid fibrils in vitro. Biol Psychiatry 52, 880-886.

[45] Berendsen HJC, van der Spoel D, van Drunen, D (1995) GROMACS: A message-passing parallel molecular dynamics implementation. Computer Physics Communications 91, 43-56.

[46] Schuettelkopf AW, van Aalten DMF (2004) PRODRG - a tool for high-throughput crystallography of protein-ligand complexes. Acta Crystallographica 60, 1355-1363.

[47] Miyamoto S, Kollman PA (1992) SETTLE: An analytical version of the SHAKE and RATTLE algorithms for rigid water models. J Comp Chem 13, 952-962.

[48] Hess B, Bekker H, Berendsen HJC, Fraaije JGEM (1997) LINCS: A linear constraint solver for molecular simulations. J Comp Chem 18, 1463-1472.

[49] Darden TA, York D, Pedersen L (1993) Particle mesh Ewald: An $\mathrm{N} \cdot \log (\mathrm{N})$ method for Ewald sums in large systems. J Chem Physics 98, 10089-10092.

[50] York DM, Wlodawer A, Pedersen LG, Darden TA (1994) Atomic-level accuracy in simulations of large protein crystals. Proc Natl Acad Sci U S A 91, 8715-8718.

[51] Kabsch W, Sander C (1983) Dictionary of protein secondary structure: pattern recognition of hydrogen-bonded and geometrical features. Biopolymers 22, 2577-2637.
[52] Daura X, van Gunsteren WF, Mark AE (1999) Foldingunfolding thermodynamics of a beta-heptapeptide from equilibrium simulations. Proteins 34, 269-280.

[53] Gomez de Barreda E, Perez M, Gomez Ramos P, de Cristobal J, Martin-Maestro P, Moran A, Dawson HN, Vitek MP, Lucas JJ, Hernandez F, Avila J (2010) Tau-knockout mice show reduced GSK3-induced hippocampal degeneration and learning deficits. Neurobiol Dis 37, 622-629.

[54] Lockman PR, McAfee G, Geldenhuys WJ, van der Schyf CJ, Abbruscato TJ, Allen DD (2005) Brain uptake kinetics of nicotine and cotinine after chronic nicotine exposure. J Pharmacol Exp Ther 314, 636-642.

[55] Riah O, Courriere P, Dousset JC, Todeschi N, Labat C (1998) Nicotine is more efficient than cotinine at passing the bloodbrain barrier in rats. Cell Mol Neurobiol 18, 311-318.

[56] Lambert MP, Barlow AK, Chromy BA, Edwards C, Freed R, Liosatos M, Morgan TE, Rozovsky I, Trommer B, Viola KL, Wals P, Zhang C, Finch CE, Krafft GA, Klein WL (1998) Diffusible, nonfibrillar ligands derived from Abeta1-42 are potent central nervous system neurotoxins. Proc Natl Acad Sci U S A 95, 6448-6453.

[57] Ferreira ST, Vieira MN, de Felice FG (2007) Soluble protein oligomers as emerging toxins in Alzheimer's and other amyloid diseases. IUBMB Life 59, 332-345.

[58] Hatsukami D, Lexau B, Nelson D, Pentel PR, Sofuoglu M, Goldman A (1998) Effects of cotinine on cigarette selfadministration. Psychopharmacology (Berl) 138, 184-189.

[59] Hatsukami DK, Grillo M, Pentel PR, Oncken C, Bliss R (1997) Safety of cotinine in humans: physiologic, subjective, and cognitive effects. Pharmacol Biochem Behav 57, 643-650.

[60] Olcese JM, Cao C, Mori T, Mamcarz MB, Maxwell A Runfeldt MJ, Wang L, Zhang C, Lin X, Zhang G, Arendash GW (2009) Protection against cognitive deficits and markers of neurodegeneration by long-term oral administration of melatonin in a transgenic model of Alzheimer disease. $J$ Pineal Res 47, 82-96.

[61] Takashima A (2006) GSK-3 is essential in the pathogenesis of Alzheimer's disease. J Alzheimers Dis 9, 309-317.

[62] Hooper C, Killick R, Lovestone S (2008) The GSK3 hypothesis of Alzheimer's disease. J Neurochem 104, 1433-1439.

[63] Plattner F, Angelo M, Giese KP (2006) The roles of cyclindependent kinase 5 and glycogen synthase kinase 3 in tau hyperphosphorylation. J Biol Chem 281, 25457-25465.

[64] Baum L, Hansen L, Masliah E, Saitoh T (1996) Glycogen synthase kinase 3 alteration in Alzheimer disease is related to neurofibrillary tangle formation. Mol Chem Neuropathol 29, 253-261.

[65] Jan A, Gokce O, Luthi-Carter R, Lashuel HA (2008) The ratio of monomeric to aggregated forms of Abeta40 and Abeta42 is an important determinant of amyloid-beta aggregation, fibrillogenesis, and toxicity. J Biol Chem 283, 28176-28189.

[66] Kim J, Onstead L, Randle S, Price R, Smithson L, Zwizinski C, Dickson DW, Golde T, McGowan E (2007) Abeta40 inhibits amyloid deposition in vivo. J Neurosci 27, 627-633.

[67] Kumar-Singh S, Theuns J, van Broeck B, Pirici D, Vennekens K, Corsmit E, Cruts M, Dermaut B, Wang R, van Broeckhoven C (2006) Mean age-of-onset of familial Alzheimer disease caused by presenilin mutations correlates with both increased Abeta42 and decreased Abeta40. Hum Mutat 27, 686-695.

[68] Arendash GW, Sanchez-Ramos J, Mori T, Mamcarz M, Lin X, Runfeldt M, Wang L, Zhang G, Sava V, Tan J, Cao C (2010) Electromagnetic field treatment protects against and reverses cognitive impairment in Alzheimer's disease mice. $J$ Alzheimers Dis 19, 191-210. 
[69] Szymanska I, Radecka H, Radecki J, Kaliszan R (2007) Electrochemical impedance spectroscopy for study of amyloid beta-peptide interactions with (-) nicotine ditartrate and (-) cotinine. Biosens Bioelectron 22, 1955-1960.

[70] de Felice FG, Wasilewska-Sampaio AP, Barbosa AC, Gomes FC, Klein WL, Ferreira ST (2007) Cyclic AMP enhancers and Abeta oligomerization blockers as potential therapeutic agents in Alzheimer's disease. Curr Alzheimer Res 4, 263 271.

[71] Walsh DM, Selkoe DJ (2007) A beta oligomers - a decade of discovery. J Neurochem 101, 1172-1184.

[72] Haass C, Selkoe DJ (2007) Soluble protein oligomers in neurodegeneration: lessons from the Alzheimer's amyloid beta-peptide. Nat Rev Mol Cell Biol 8, 101-112.

[73] Tabaton M, Gambetti P (2006) Soluble amyloid-beta in the brain: the scarlet pimpernel. J Alzheimers Dis 9, 127132.

[74] Echeverria V, Ducatenzeiler A, Dowd E, Janne J, Grant SM, Szyf M, Wandosell F, Avila J, Grimm H, Dunnett SB, Hartmann T, Alhonen L, Cuello AC (2004) Altered mitogenactivated protein kinase signaling, tau hyperphosphorylation and mild spatial learning dysfunction in transgenic rats expressing the beta-amyloid peptide intracellularly in hippocampal and cortical neurons. Neuroscience 129, 583-592.

[75] Rangachari V, Moore BD, Reed DK, Sonoda LK, Bridges AW, Conboy E, Hartigan D, Rosenberry TL (2007) Amyloidbeta(1-42) rapidly forms protofibrils and oligomers by distinct pathways in low concentrations of sodium dodecylsulfate. Biochemistry 46, 12451-12462.

[76] Mastrangelo IA, Ahmed M, Sato T, Liu W, Wang C, Hough P, Smith SO (2006) High-resolution atomic force microscopy of soluble Abeta42 oligomers. J Mol Biol 358, 106-119.

[77] Kirschner DA, Gross AA, Hidalgo MM, Inouye H, Gleason KA, Abdelsayed GA, Castillo GM, Snow AD, Pozo-Ramajo
A, Petty SA, Decatur SM (2008) Fiber diffraction as a screen for amyloid inhibitors. Curr Alzheimer Res 5, 288-307.

[78] Antzutkin ON, Balbach JJ, Tycko R (2003) Site-specific identification of non-beta-strand conformations in Alzheimer's beta-amyloid fibrils by solid-state NMR. Biophys $J \mathbf{8 4}$, 3326-3335.

[79] Yu J, Bakhos L, Chang L, Holterman MJ, Klein WL, Venton DL (2002) Per-6-substituted beta-cyclodextrin libraries inhibit formation of beta-amyloid-peptide (A beta)-derived, soluble oligomers. J Mol Neurosci 19, 51-55.

[80] Yang F, Lim GP, Begum AN, Ubeda OJ, Simmons MR, Ambegaokar SS, Chen PP, Kayed R, Glabe CG, Frautschy SA, Cole GM (2005) Curcumin inhibits formation of amyloid beta oligomers and fibrils, binds plaques, and reduces amyloid in vivo. J Biol Chem 280, 5892-5901.

[81] Yao Z, Drieu K, Papadopoulos V (2001) The Ginkgo biloba extract EGb 761 rescues the PC12 neuronal cells from betaamyloid-induced cell death by inhibiting the formation of beta-amyloid-derived diffusible neurotoxic ligands. Brain Res 889, 181-190.

[82] de Felice FG, Vieira MN, Saraiva LM, Figueroa-Villar JD, Garcia-Abreu J, Liu R, Chang L, Klein WL, Ferreira ST (2004) Targeting the neurotoxic species in Alzheimer's disease: inhibitors of Abeta oligomerization. FASEB $J \mathbf{1 8}$, 1366-1372.

[83] Zhao W, Wang J, Ho L, Ono K, Teplow DB, Pasinetti GM (2009) Identification of antihypertensive drugs which inhibit amyloid-beta protein oligomerization. J Alzheimers Dis 16, 49-57.

[84] Hou Y, Aboukhatwa MA, Lei DL, Manaye K, Khan I, Luo Y (2010) Anti-depressant natural flavonols modulate BDNF and beta amyloid in neurons and hippocampus of double TgAD mice. Neuropharmacology 58, 911-920. 